\title{
Enzymatic non-covalent synthesis of a versatile platform for bioorthogonal prodrugs activation to combat drug resistance
}

\author{
Qingxin Yao, ${ }^{1,3}$ Shuo Gao, ${ }^{2}$ Chengling Wu, ${ }^{1}$ Ting Lin ${ }^{2, *}$ and Yuan Gao ${ }^{1,3, *}$ \\ ${ }^{1}$ CAS Center for Excellence in Nanoscience, CAS Key Laboratory of Biomedical Effects of Nanomaterials and Nanosafety, \\ National Center for Nanoscience and Technology, Beijing 100190, China; \\ ${ }^{2}$ Fujian Provincial Key Laboratory of Innovative Drug Target Research, School of Pharmaceutical Sciences, Xiamen \\ University, Xiamen 361102, China; \\ ${ }^{3}$ University of Chinese Academy of Sciences, Beijing 100049, China. \\ *E-mail: gaoy@nanoctr.cn; linting@xmu.edu.cn
}

\begin{abstract}
Multidrug resistance (MDR) often leads to the failure of the anticancer treatment. Besides the blockage of those MDR pathways, the development of more potent drugs are of urgent needs but largely postponed due to imbalance between safety and efficacy. The prodrug strategy, especially with bioorthogonal activation has shown immerse potential to balance safety and efficacy, while recent studies focus on few drug entities such as doxorubicin and MMAE, leaving the vast collection of toxins undetermined. Here we have enumerated typical molecular entities ranging from FDA approved drugs (doxorubicin, paclitaxel) to a heated ADC warhead (MMAF-OMe) and a trichothecene toxin (Mytoxin A) to demonstrate that the trans-cyclooctene (TCO) caging may serve as a general prodrug design to increase the therapeutic index for bioactive molecules. These prodrugs can be efficiently activated on-demand by the bioorthogonal activators whose distribution is regulated by the cell specific enzymatic non-covalent synthesis of supramolecular self-assemblies. These cell-specific prodrugs activation could not only reduce the toxicology of drugs but also enhance the synergistic therapeutic effect within a broad range of dose ratio. More importantly, these prodrugs activation share the same activator bearing assemblies, which allows the flexible shift of drug identities to successfully combat MDR cancer in vivo. In general, this versatile bioorthogonal prodrug activation platform is readily applicable to enlarge the therapeutic window for various bioactive molecules. We envision that the spatiotemporal controlled prodrug activation should facilitate the drug discovery and development.
\end{abstract}

Keywords: Enzyme; Self-assembly; Bioorthogonal prodrug; Therapeutic window; Multidrug resistance

\section{Introduction}

The advent of multidrug resistance is likely inevitable in cancer therapy. ${ }^{1}$ Though the better understanding of cancer biology would elucidate the mechanisms of inherent or acquired resistance, ${ }^{2}$ the heterogeneity within tumor cells harbor many rare or uncommon gene alterations which demand newer or more potent anticancer drugs for effective treatment at the time of emergence of resistance. ${ }^{3}$ However, the discovery of new anticancer drugs is hindered with the highest failure rate among all therapeutic areas. The major reasons for clinical trials terminations are the unattainable balance between efficacy and 
safety. ${ }^{4}$ The requirement of both sufficient efficacy and safety are critical but the anticancer leading compounds based on structure-activity relationship screening are usually highly potent chemical entities. ${ }^{5}$ Such a dilemma in drug discovery motivated the precision medicine with a number of alternative strategies including antibody-drug conjugates (ADCs, e.g., Kadcyla ${ }^{6}$ ) and nanomedicines (e.g., Doxil ${ }^{7}$, Abraxane $^{8}$ ). With the underlying active and passive targeting mechanisms, the targeted drug delivery aimed to increase the selective distribution of active drugs between tumor and non-tumor yet with many uncertainties. For examples, the development of ADCs should make a set of integrated choice to select the best target antigens, optimized linkers and suitable cytotoxic compounds before making the designed conjugate with engineered antibodies. ${ }^{9}$ Similarly, nanomedicines would orchestrate delivery vehicles, cargos, loading capacities, release kinetics and delivery efficiency. ${ }^{10-11}$ Although the significant progressions in biology, informatics and engineering may assist each individual choice in a data-driven manner, the outcomes of the whole conjugates remain hard to predict due to the challenges of translating in vitro hits into in vivo leads. ${ }^{12}$

In contrast, a two-step prodrug activation strategy is more versatile. The first step conveys the targeting to disease site and the second step generates active toxins locally, ${ }^{13-17}$ in which certain bioorthogonal decaging reactions guarantee the specificity of prodrug activation thus avoid off-target toxicity. ${ }^{18}$ Beyond the few investigated drugs, ${ }^{19}$ we hypothesize that the two-step prodrug activation is a general strategy to expand the therapeutic window for drug-like molecules. This hypothesis is grounded in two perceptions: (1) the trans-cyclooctene (TCO) is capable to cage not only amine but also hydroxyl, ${ }^{20}$ (2) amine or hydroxyl groups present on most anticancer drugs for its anchoring to biomacromolecules (protein/DNA target) through hydrogen bonding. ${ }^{21-22}$ Hence, we enumerated a list of typical biologically active molecules ranging from FDA approved drugs (doxorubicin, paclitaxel), to one of the most popular ADC toxins (MMAF-OMe) and a life-threaten trichothecene mycotoxin with medicinal value (Mytoxin $A^{23}$ ). (Scheme 1) In combination with the cancer specific tetrazine (Tz) bearing assemblies via enzymatic noncovalent synthesis, ${ }^{24-27}$ we showed that the two-step prodrug activation strategy could increase the therapeutic index by minimizing the cytotoxicity against normal cells and selectively activating prodrugs in cancer cells. In addition, the activation of co-administrated prodrugs demonstrated enhanced synergistic effect over active drug pairs. Animal studies further demonstrated that the bioorthogonal prodrug activation platform allowed the flexible shift of drug identities (from resisted to highly potent drug) to combat drug resistance in a single treatment. Together, this work proved the applicability of assemblies directed TCO-Tz bioorthogonal decaging reaction to enlarge the therapeutic window for a broad scope of bioactive molecular entities. With the merit of on-demand prodrugs activation, we envision that the two-step prodrug activation strategy should provide a general platform to facilitate the search of drugs in chemical space to combat drug resistance. ${ }^{28}$ 


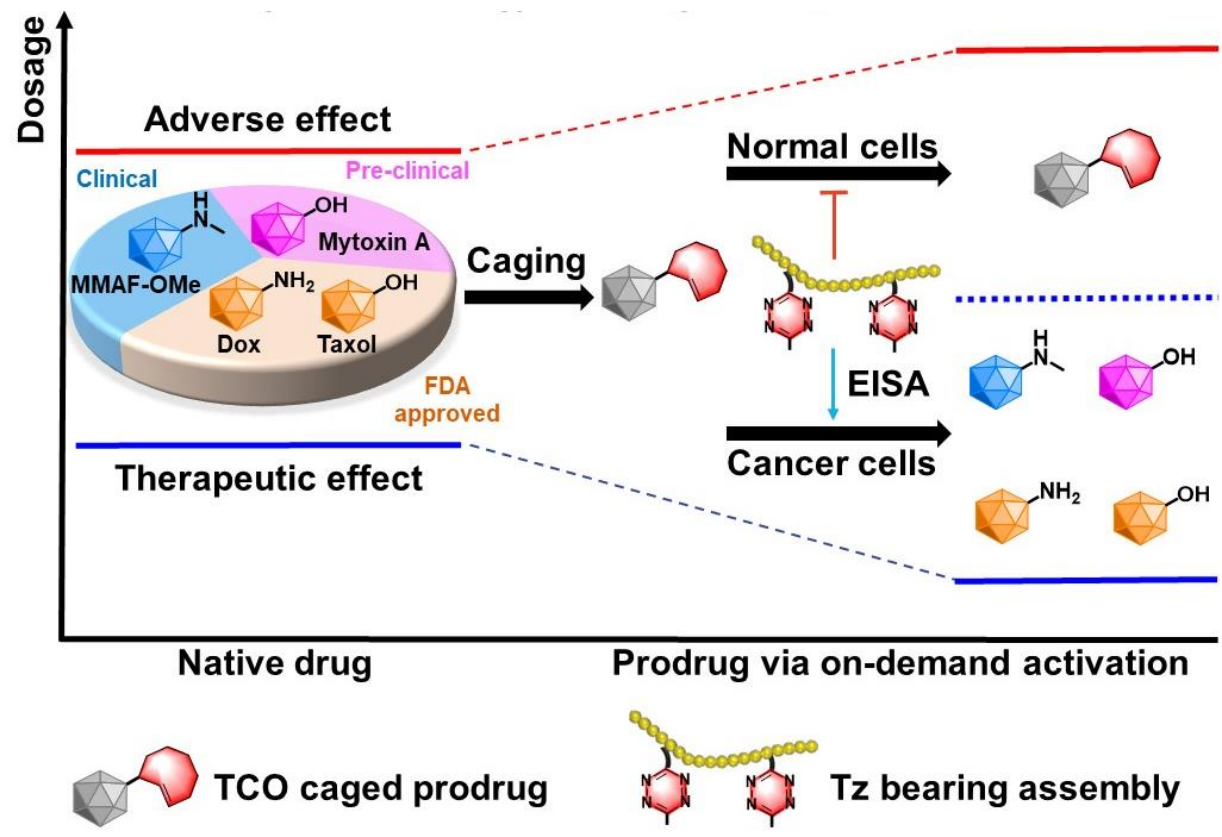

Scheme 1. Enlarge the therapeutic window of typical toxins via the process of EISA mediated on-demand prodrug activation. EISA: enzyme-instructed supramolecular self-assemblies.

\section{Results and discussion}

(A)
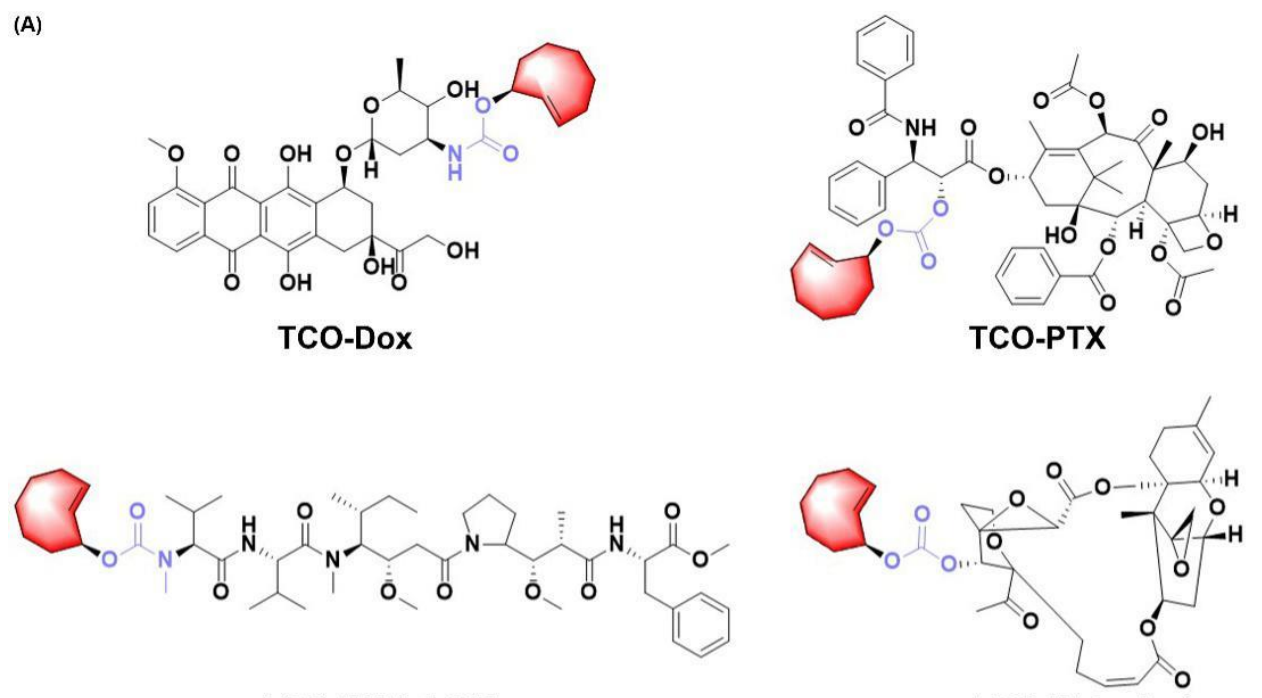

TCO-MMAF-OMe

TCO-Mytoxin A

(B)
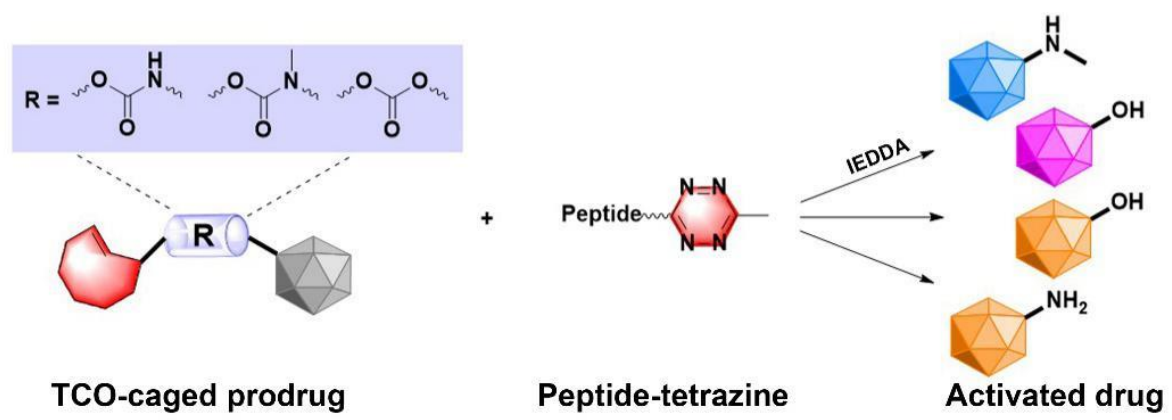

Scheme 2. (A) Molecular structures of bioactive molecules and the corresponding TCO caged prodrugs.

(B) The general prodrug activation reaction. 
In accordance with the above analysis, we and other groups have prepared the bioorthogonal prodrug of TCO-Dox via the conjugation of trans-cyclooctene (TCO) to doxorubicin (Dox) (Scheme 2A), showing the alleviated side effect. $^{13}$ The TCO cage could be efficiently removed by Tz via the fast inverse-electron-demand Diels-Alder (IEDDA) reaction (Scheme 2B). ${ }^{29}$ Then, we expanded the applicability of this click-to-release chemistry in prodrug approaches by modifying other typical molecular entities with secondary amine and hydroxyl groups, such as paclitaxel (PTX), monomethyl auristatin F methyl ester (MMAF-OMe) and Mytoxin A. Among them, paclitaxel is a FDA approved anticancer drug as tubulin stabilizer. MMAF-OMe is a potent tubulin polymerization inhibitor which is similar to MMAE but with better cell penetration efficiency. Mytoxin $A$ is a life-threaten trichothecene mycotoxin with medicinal value. With proper synthetic routes (to see $\mathrm{SI}$ ), we set out to further synthesize TCO caged prodrugs TCO-PTX, TCO-MMAF-OMe and TCO-Mytoxin A with the yields of $86.1 \%, 51.1 \%, 15.8 \%$, respectively. (Scheme 2A)
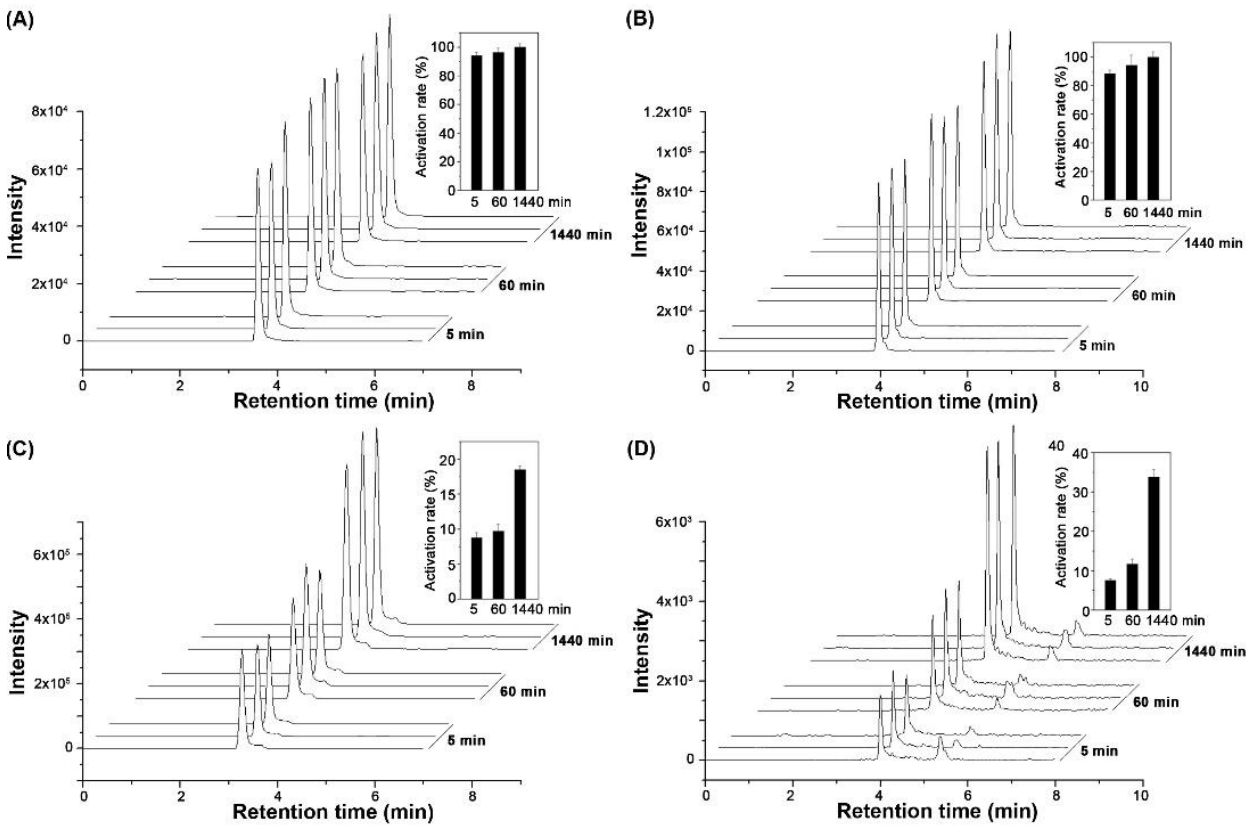

Figure 1. In vitro activation of prodrugs (A) TCO-Dox, (B) TCO-PTX, (C) TCO-MMAF-OMe and (D) TCO-Mytoxin A by NapFFYpK-Tz. After mixing $100 \mu \mathrm{L}$ of $0.5 \mu \mathrm{M}$ TCO caged prodrug with $100 \mu \mathrm{L}$ of 1.0 $\mu \mathrm{M}$ NapFFYpK-Tz in PBS buffer at $37^{\circ} \mathrm{C}$, the reaction mixture was analyzed by UPLC-MS/MS at different time intervals.

Next, we applied UPLC-MS/MS to determine the activation of prodrugs TCO-Dox, TCO-PTX, TCO-MMAF-OMe and TCO-Mytoxin A by NapFFYpK-Tz in vitro. As shown in Figure 1A, the LC trace clearly showed the emerging peak of Dox 5 min post mixing TCO-Dox with NapFFYpK-Tz. Extended incubation from $5 \mathrm{~min}$ to $1440 \mathrm{~min}$ increased less than $6 \%$ of activated Dox (from $94.3 \%$ to $100 \%$ ), indicating very efficient liberation of Dox within $5 \mathrm{~min}$. Similarly, the payload of PTX was readily released from TCO-PTX with an activation rate of $88.4 \%$ within after 5 min (Figure 1B). Surprisingly, in the case of TCO-MMAF-OMe and TCO-Mytoxin A, lower activation rate of $18.5 \%$ and $33.8 \%$ at 1440 min were observed (Figure 1C-D). The slower activation of TCO-MMAF-OMe and TCO-Mytoxin A was possibly due to the steric hindrance to affect the tautomerization rates, ${ }^{20}$ which led to lower apparent toxicity. (vide 
infra)

\section{Enzymatic non-covalent synthesis of prodrug activation platform}

(A)
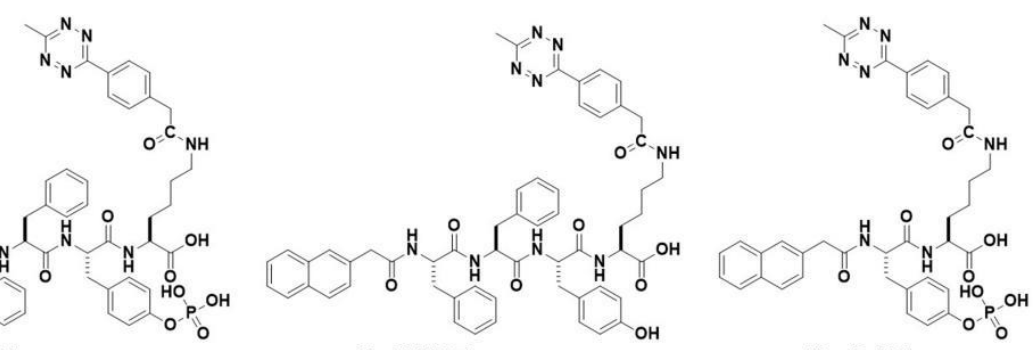

NapFFYpK-Tz

NapFFYK-Tz

NapYpK-Tz
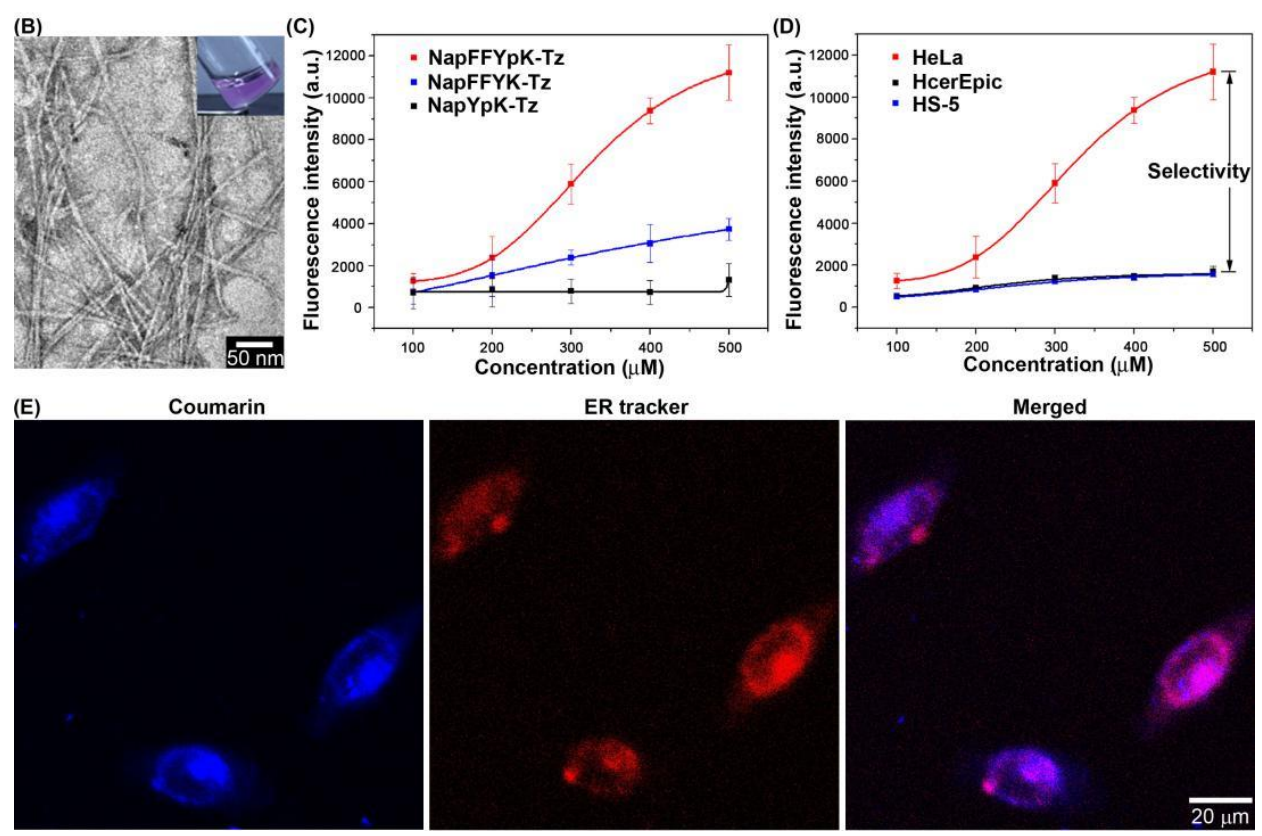

Merged

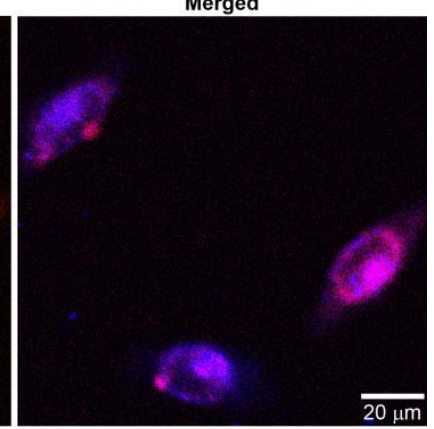

Figure 2. (A) Molecular structure of the Tz bearing self-assembly precursors. (B) TEM image of the nanofibers within the transparent purple hydrogel of NapFFYK-Tz (inset). The hydrogel was prepared from $1.0 \mathrm{mg} / \mathrm{mL}$ of NapFFYpK-Tz at $\mathrm{pH}=7.4$ with addition of $10 \mathrm{U} / \mathrm{mL}$ of alkaline phosphatase. (C) Accumulation of Tz bearing self-assembly precursors in live HeLa cells. HeLa cells were pre-incubated with $100-500 \mu \mathrm{M}$ self-assembly precursors for $6 \mathrm{~h}$, rinsed with PBS and incubated with $100 \mu \mathrm{L}$ of $50 \mu \mathrm{M}$ of TCO-CMR for $24 \mathrm{~h}(\mathrm{n}=6$ ). (D) Restored fluorescence intensity of coumarin in HeLa, HcerEpic and HS-5 cells. Cells were pre-incubated with 100-500 $\mu \mathrm{M}$ NapFFYpK-Tz for $6 \mathrm{~h}$, rinsed with PBS and incubated with $100 \mu \mathrm{L}$ of $50 \mu \mathrm{M}$ of TCO-CMR for $24 \mathrm{~h}(\mathrm{n}=6)$. (E) CLSM images showed the distribution of liberated coumarin (blue) and its overlap with ER tracker (red). HeLa cells were pre-incubated with $2 \mathrm{~mL}$ of $500 \mu \mathrm{M}$ NapFFYpK-Tz for $6 \mathrm{~h}$, rinsed with PBS and then incubated with $2 \mathrm{~mL}$ of pre-warmed staining solution (500 $\mathrm{nM}$ ER-Tracker ${ }^{\mathrm{TM}}$ Red dye) for $30 \mathrm{~min}$. Then $1 \mathrm{~mL}$ of $50 \mu \mathrm{M}$ TCO-CMR was added and the fluorescent images were captured 5 min later.

We designed a series of Tz bearing molecules (namely NapFFYpK-Tz, NapFFYK-Tz and NapYpK-Tz, Figure $2 \mathrm{~A}$ ) as prodrug triggers with different self-assembly propensity. After dephosphorylation, NapFFYpK-Tz can form a transparent hydrogel with a network of uniform nanofibers (Figure $2 \mathrm{~B}$ ) and the critical hydrogelation concentration was $0.5 \mathrm{mg} / \mathrm{mL}$ (Figure S1). In contrast, NapYpK-Tz transformed into precipitate after addition of ALP (Figure S2) and no nanofiber was observed under TEM (Figure S3). The 
solution of NapFFYK-Tz could form soft hydrogel with a network of nanofibers by adjusting the pH to 6.5. (Figure S4\&5)

To measure the selective accumulation of Tz inside cancer cells, we adopted the fluorescence liberation test via the fluorogenic TCO-CMR. ${ }^{30}$ As shown in Figure $2 \mathrm{C}$, in contrast to a minuscule fluorescence restored in HeLa cells pre-incubated with NapYpK-Tz, the emission increased significantly in HeLa cells pre-incubated with NapFFYpK-Tz, confirming the accumulation of Tz. However, the direct incubation with the hydrogelator NapFFYK-Tz only yielded a slight emission increase, indicating formation of few assemblies without enzymatic transformation in biological environment. ${ }^{31}$ Therefore, NapFFYpK-Tz was selected for further investigation in cell selective formation of EISA. According to Figure 2D, different from HeLa cells, the HcerEpic cells and HS-5 cells only liberated ignorable amount of fluorescence even pre-incubated with $500 \mu \mathrm{M}$ NapFFYpK-Tz, implying that EISA barely formed in these two normal cell lines. Therefore, EISA of NapFFYpK-Tz could differentiate the cancer cells from normal cells, which was dependent on the over-expression of phosphatase in HeLa cells. ${ }^{32}$

Further, we used confocal laser scanning microscope (CLSM) to visualize the location of EISA. A bright fluorescent area appeared inside HeLa cells within $5 \mathrm{~min}$, which indicated the high reactivity of the accumulated Tz on intracellular EISA and its co-localization with the ER after a co-staining by an ER tracker. (Figure 2E)

\section{Prodrug activation in live cells}
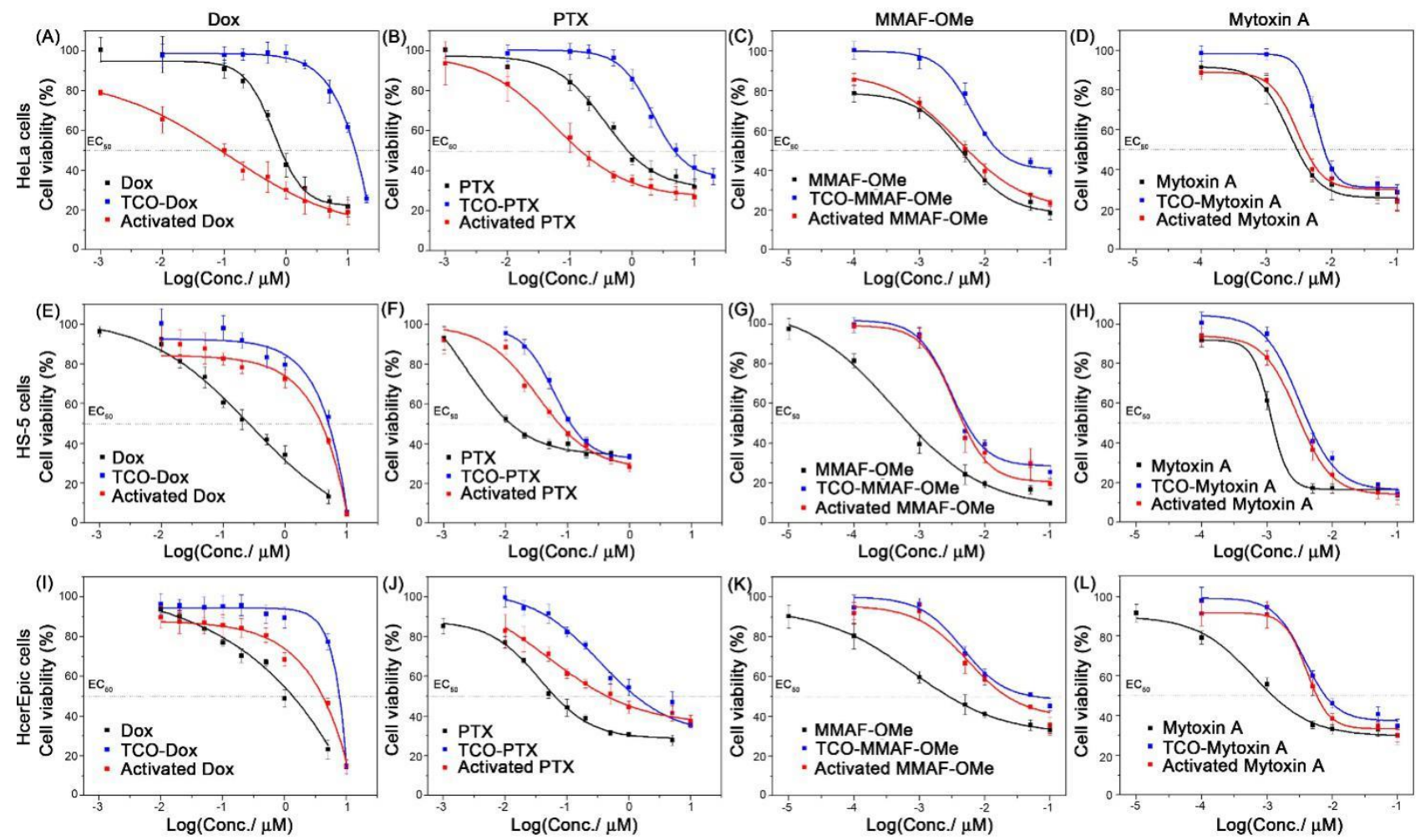

Figure 3. 72 h cytotoxicity of drugs against (A-D) HeLa cells, (E-H) HS-5 cells and (I-L) HcerEpic cells. Cytotoxicity profiles of active drug (black line) and TCO caged drug (blue line) were obtained by incubating cells with different concentrations of each compound for $72 \mathrm{~h}$. For the cytotoxicity profile of activated drugs (red line), cells were pre-incubated with $100 \mu \mathrm{L}$ of $500 \mu \mathrm{M}$ NapFFYpK-Tz for $6 \mathrm{~h}$ followed 
by incubation with $200 \mu \mathrm{L}$ of TCO modified drugs at different concentrations for $72 \mathrm{~h}(n=6)$.

Before studying prodrug activation in live cells, all three tested cell lines were incubated with $500 \mu \mathrm{M}$ NapFFYpK-Tz for $72 \mathrm{~h}$ gave the cell viability $>85 \%$, which confirmed the biocompatibility of NapFFYpK-Tz and the corresponding intracellular assemblies and thus eligible for further prodrug activation in live cells. (Figure S6) We next evaluated the anticancer efficacy of activating the TCO caged prodrugs with active drugs as reference. As shown in Figure 3 and Table 1, all of the TCO caged prodrugs were much less effective than their native drugs for cell growth inhibition, exhibiting 2-21 times higher $E_{50}$, which validated the reduced potency via TCO caging. While incorporated with EISA, $E_{50}$ of the activated Dox was as low as $0.087 \mu \mathrm{M}$ in HeLa cells, representing a 150 -fold increase of cytotoxicity compared with that of the TCO-Dox prodrug alone $(13.086 \mu \mathrm{M})$. This dramatically enhanced cytotoxicity indicated that TCO-Dox were effectively activated in HeLa cells. Moreover, the cytotoxicity of the activated Dox was approximately 9 times higher than active Dox, which was likely due to high local concentration of activated drugs via fast activation process. Similar results were obtained for TCO-PTX as the cytotoxicity of activated PTX $\left(E_{50}: 0.152 \mu \mathrm{M}\right)$ demonstrated 30-fold and 5-fold enhancement compared with TCO-PTX $\left(E_{50}: 4.692 \mu \mathrm{M}\right)$ and active PTX $\left(E_{50}: 0.880 \mu \mathrm{M}\right)$, respectively. Since TCO-MMAF-OMe and TCO-Mytoxin A endured slow activation in vitro (Figure 1C-D), the apparent cytotoxicity of the activated MMAF-OMe and Mytoxin A just restored close to the native ones. More importantly, with negligible EISA in HS-5 cells and HcerEpic cells, the prodrugs were barely activated. The prodrugs after "activation process" were much less potent than native drugs in these two normal cell lines.

Table 1. Calculated $\mathrm{EC}_{50}{ }^{\mathrm{a}}$ values of drugs against HeLa cells, HS-5 cells and HcerEpic cells.

\begin{tabular}{|c|c|c|c|c|c|}
\hline Cell lines & Drugs & Dox & PTX & MMAF-OMe & Mytoxin A \\
\hline & Active & 0.825 & 0.880 & 0.00425 & 0.00291 \\
\hline \multirow[t]{3}{*}{ HeLa } & TCO caged & 13.086 & 4.692 & 0.0161 & 0.00688 \\
\hline & Activated $^{\mathrm{b}}$ & 0.087 & 0.152 & 0.00551 & 0.00396 \\
\hline & Active & 0.264 & 0.0122 & 0.000681 & 0.00121 \\
\hline \multirow[t]{3}{*}{ HS-5 } & TCO caged & 5.120 & 0.113 & 0.00520 & 0.00430 \\
\hline & Activated $^{\mathrm{b}}$ & 3.839 & 0.0721 & 0.00462 & 0.00328 \\
\hline & Active & 1.379 & 0.0637 & 0.00293 & 0.00121 \\
\hline \multirow[t]{2}{*}{ HcerEpic } & TCO caged & 7.597 & 1.292 & 0.0626 & 0.00793 \\
\hline & Activated $^{\mathrm{b}}$ & 4.115 & 0.441 & 0.0225 & 0.00576 \\
\hline
\end{tabular}

${ }^{a} E C_{50}$ values are determined by the $72 \mathrm{~h}$ cytotoxicity of each drug. The units of $\mathrm{EC}_{50}$ are in $\mu \mathrm{M}$.

${ }^{\mathrm{b}}$ Activated drug indicates that cells were pre-incubated with $100 \mu \mathrm{L}$ of $500 \mu \mathrm{M}$ NapFFYpK-Tz for $6 \mathrm{~h}$ and then incubated with $200 \mu \mathrm{L}$ of TCO modified drug at different concentrations for $72 \mathrm{~h}$. 

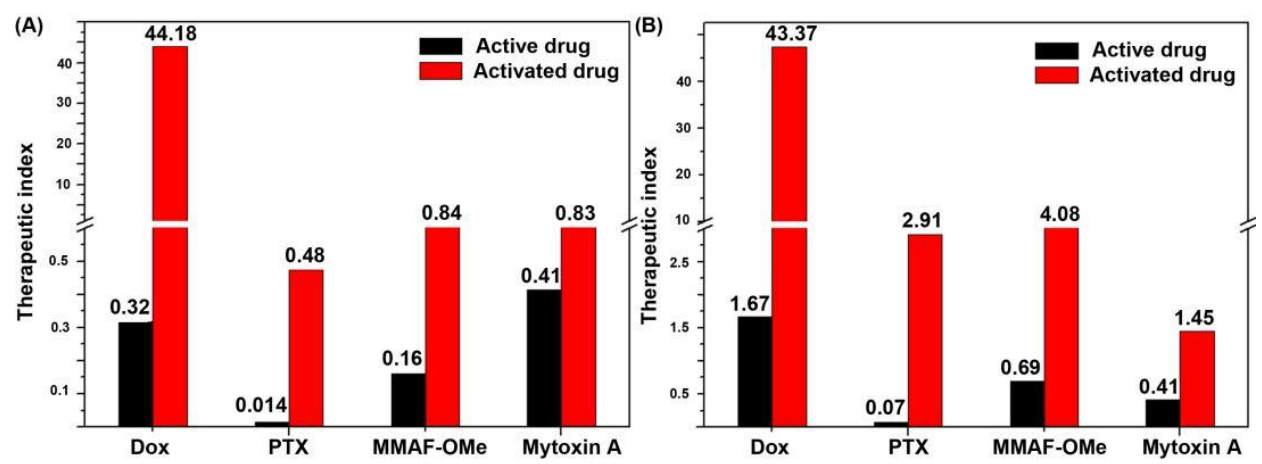

Figure 4. Calculated therapeutic index based on the ratio of $\mathrm{EC}_{50}$ between (A) HS-5/ HeLa cells and (B) HcerEpic / HeLa cells.

To better illustrate the advantages of EISA directed prodrugs activation, we calculated the therapeutic index which was defined as the ratio of the $\mathrm{EC}_{50}$ against normal cells over $\mathrm{EC}_{50}$ against cancer cells. According to Figure 4, the therapeutic index of all four activated drugs were increased significantly compared with their active drugs, confirming the advantage of the EISA-directed prodrug activation to improve the safety of drugs.

\section{Activation of prodrugs combination}
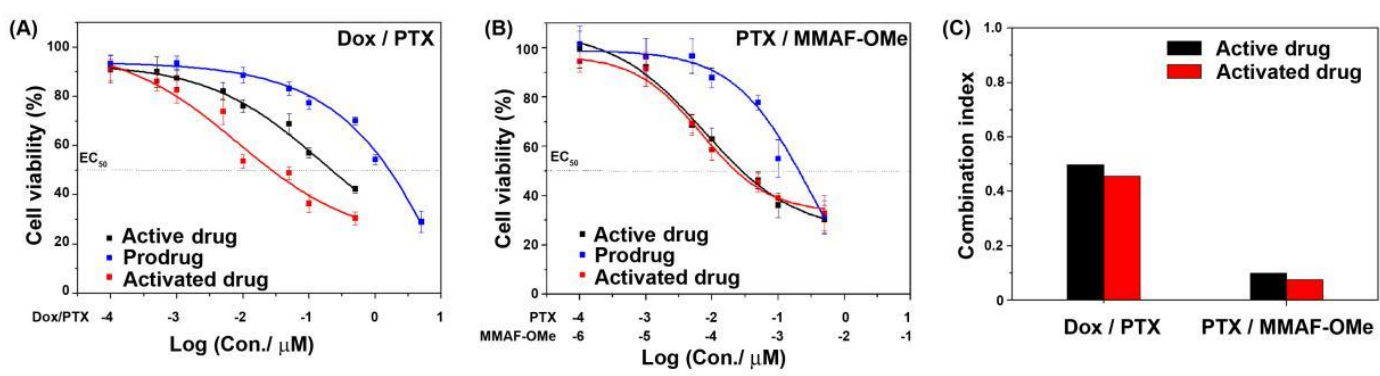

Figure 5. Combinatory activation of (A) Dox / PTX and (B) PTX / MMAF-OMe against HeLa cells. Dox / PTX was fixed at a molar ratio of 1:1; PTX / MMAF-OMe was fixed at a molar ratio of 100:1. Cytotoxicity profiles were obtained by incubating cells with different concentrations of each combined drugs for $72 \mathrm{~h}$. For the activated drugs, cells were pre-incubated with $100 \mu \mathrm{L}$ of $500 \mu \mathrm{M}$ NapFFYpK-Tz for $6 \mathrm{~h}(\mathrm{n}=6)$. (C) Combination index of Dox / PTX and PTX / MMAF-OMe.

Systemic combination therapy is also intrinsically useful for cancer treatment. ${ }^{33}$ As expected for prodrug design, the combination of prodrugs (TCO-Dox / TCO-PTX and TCO-PTX / TCO-MMAF-OMe) were much less effective at cell growth inhibition compared with the combination of active drugs. In contrast, the combination of activated Dox / PTX exhibited much higher potency against HeLa cells than that of active drugs, indicating the effective activation of both combined prodrugs (Figure 5A). The activated PTX / MMAF-OMe gave slightly higher potency than their native drugs, which may be due to the slow activation of TCO-MMAF-OMe (Figure 5B).

To quantify the synergistic effect of drug combination, we measured the drug combination index (Cl) based on Chou and Talalay's formula. ${ }^{34}$ As shown in Figure 5C, the Cl of activated Dox / PTX and activated PTX / MMAF-OMe against HeLa cells were similar to their active drugs combinations (smaller than 1.0). This reservation of the synergistic effect indicated that the prodrug activation will not alter the mechanism of drug actions. 


\section{Shift drug identities to combat multidrug resistance}
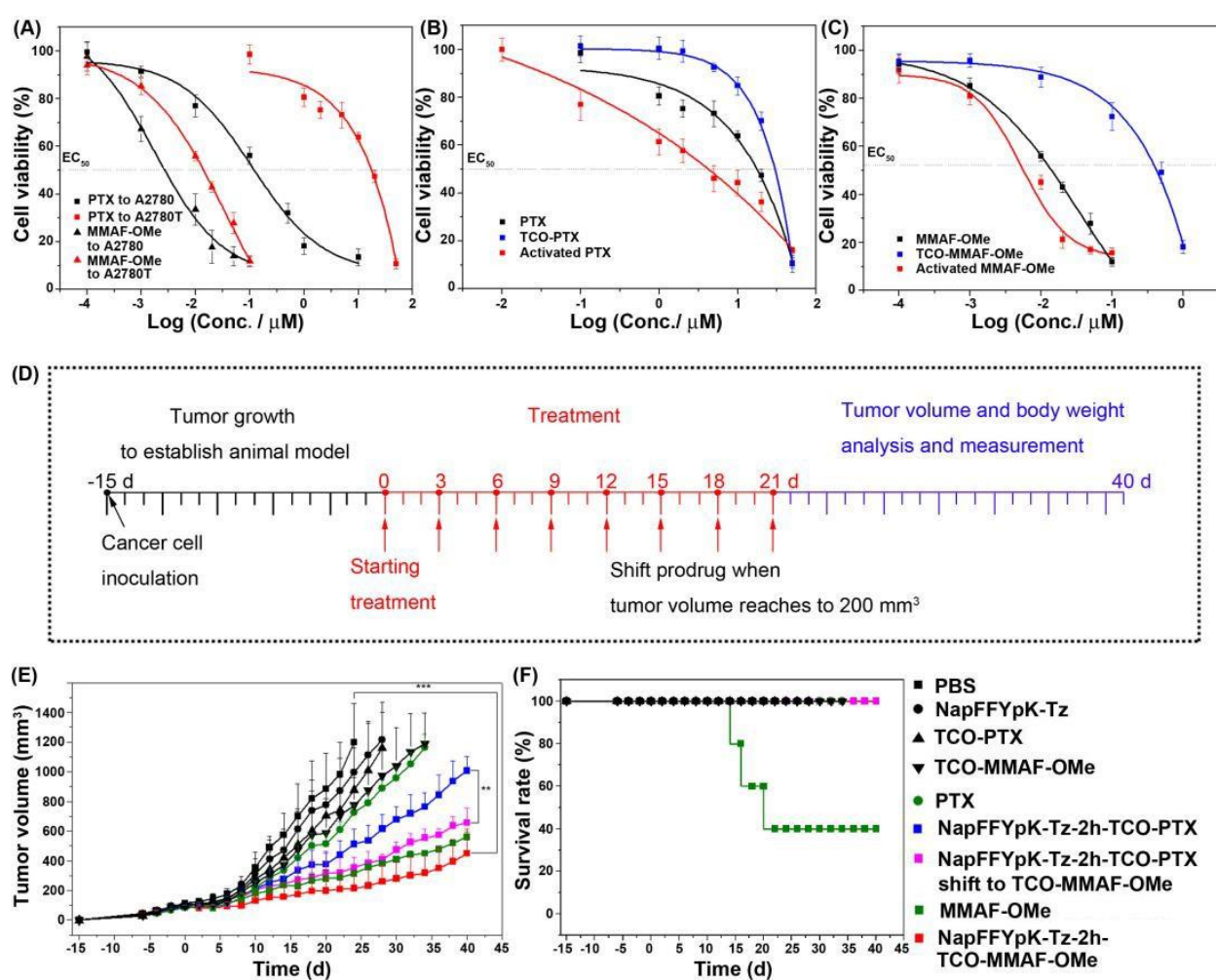

Figure 6. Prodrugs activation reverses multidrug resistance to inhibit tumor growth. (A) 72 h cytotoxicity of PTX and MMAF-OMe against A2780 and A2780T cells. Activation of TCO-PTX (B) and TCO-MMAF-OMe (C) in A2780T cells. Cytotoxicity profiles of active drug (black line) and TCO caged drug (blue line) were obtained by incubating cells with different concentrations of each compound for $72 \mathrm{~h}$. For the cytotoxicity profile of activated drugs (red line), cells were pre-incubated with $100 \mu \mathrm{L}$ of $500 \mu \mathrm{M}$ NapFFYpK-Tz for $6 \mathrm{~h}$ followed by incubation with $200 \mu \mathrm{L}$ of TCO modified drugs at different concentrations for $72 \mathrm{~h}(\mathrm{n}=6)$. (D) Schematic illustration of tumor inoculation and treatment protocol for A2780T tumor bearing mice. (E) Xenograft A2780T tumor growth curves for mice after i.v. injection of saline, $50 \mathrm{mmol} / \mathrm{Kg} \mathrm{NapFFYpK-Tz,} 10 \mathrm{mmol} / \mathrm{Kg}$ TCO-PTX, $10 \mathrm{mmol} / \mathrm{Kg}$ PTX, $0.3 \mathrm{mmol} / \mathrm{Kg} \mathrm{MMAF-OMe}$, $0.3 \mathrm{mmol} / \mathrm{Kg}$ TCO-MMAF-OMe, NapFFYpK-Tz-2h-TCO-PTX [i.v. injection of $50 \mathrm{mmol} / \mathrm{Kg}$ NapFFYpK-Tz followed by i.v. injection of $10 \mathrm{mmol} / \mathrm{Kg}$ TCO-PTX after a $2 \mathrm{~h}$ interval], NapFFYpK-Tz-2h-TCO-MMAF-OMe [i.v. injection of $50 \mathrm{mmol} / \mathrm{Kg}$ NapFFYpK-Tz followed by i.v. injection of $0.3 \mathrm{mmol} / \mathrm{Kg}$ TCO-MMAF-OMe after a $2 \mathrm{~h}$ interval] and NapFFYpK-Tz-2h-TCO-PTX shift to TCO-MMAF-OMe [i.v. injection of $50 \mathrm{mmol} / \mathrm{Kg}$ NapFFYpK-Tz followed by i.v. injection of $10 \mathrm{mmol} / \mathrm{Kg}$ TCO-PTX after a $2 \mathrm{~h}$ interval, then $10 \mathrm{mmol} / \mathrm{Kg}$ TCO-PTX shifted to $0.3 \mathrm{mmol} / \mathrm{Kg}$ TCO-MMAF-OMe after tumor volume reached to $\left.200 \mathrm{~mm}^{3}\right]\left(\mathrm{n}=5,{ }^{* *} \mathrm{P}<0.01\right.$, $\left.{ }^{* * *} \mathrm{P}<0.001\right)$. (F) Survival rate of mice in each group of $(\mathbf{E})$.

To verify the efficacy of prodrug activation in multidrug resistant tumor, we selected the typical multidrug resistant A2780/Taxol cells (MDR A2780T) as model to receive treatment of PTX and MMAF-OMe. According to Figure $6 \mathrm{~A}$, the $\mathrm{A} 2780 / \mathrm{T}$ cells were resistant to PTX ( $\mathrm{EC}_{50}$ of $\mathrm{A} 2780 \mathrm{~T}=17.30$ $\mu \mathrm{M}$ vs. $\mathrm{EC}_{50}$ of $\left.\mathrm{A} 2780=0.12 \mu \mathrm{M}\right)$. Compared with $\mathrm{A} 2780$ cells, $\mathrm{A} 2780 \mathrm{~T}$ cells displayed an increase of 
144-fold resistance to PTX. However, the A2780/T cells exhibited little resistance to MMAF-OMe (EC $\mathrm{E}_{50}$ of $\mathrm{A} 2780 \mathrm{~T}=13.9 \mathrm{nM}$ vs. $\mathrm{EC}_{50}$ of $\left.\mathrm{A} 2780=2.6 \mathrm{nM}\right)$. This result indicated that the highly potent MMAF-OMe may be used to combat paclitaxel resistant ovarian cancer. We next evaluated the activation of prodrug TCO-PTX and TCO-MMAF-OMe by pre-accumulated EISA (Figure S7) in A2780T cells. Results demonstrated that the prodrug TCO-PTX and TCO-MMAF-OMe can be effectively activated in A2780T cells with apparent increasing cytotoxicity compare to their corresponding active ones (Figure 6B-C).

Lastly, we established the paclitaxel resistant A2780/Taxol (A2780T) tumor xenograft model in $\mathrm{BALB} / \mathrm{c}$ nude mice to evaluate the antitumor efficacy in vivo. Mice were randomly divided into nine groups $(n=5)$ when the tumor volume reached $80-100 \mathrm{~mm}^{3}$ (Figure 6D). After eight courses of treatment, tumor growth was significantly inhibited in the treatment group of NapFFYpK-Tz-2h-TCO-MMAF-OMe and this antitumor effect has sustained for the entire therapeutic period (Figure 6E). In contrast, the tumor volume in the saline control group increased rapidly, and neither NapFFYpK-Tz, TCO-PTX, TCO-MMAF-OMe nor PTX alone could inhibit the tumor growth. In addition, although native MMAF-OMe could inhibit tumor growth, the direct administration of MMAF-OMe caused severe systemic toxicity, leading to a low survival rate of $40 \%$ (Figure $6 \mathrm{~F}$ ). The body weights of mice in the treatment groups remained steady, indicating the satisfied biosafety of the prodrug activation strategy (Figure S8).

Specifically on this multidrug resistant tumor model, the activated PTX demonstrated slightly better anticancer efficacy than active PTX, but it still cannot control the tumor growth. Therefore, in another group (purple line) we shifted the drug identity from TCO-PTX to TCO-MMAF-OMe. That was, when the tumor volume reached $200 \mathrm{~mm}^{3}$ in the group pre-treated with NapFFYpK-Tz-2h-TCO-PTX, the following treatment shifted to NapFFYpK-Tz-2h-TCO-MMAF-OMe. This procedure of prodrugs shifting showed significant inhibition of MDR tumor in comparison with the activated paclitaxel group, providing a convenient way to combat multidrug resistant cancer.

\section{Discussion}

Based on the enumeration of typical TCO caged prodrugs ranging from FDA approved drugs to potent natural products, we have demonstrated that the assemblies directed bioorthogonal activation of prodrugs was applicable for a vast library of toxins to significantly enlarge their therapeutic window. The co-activation of combined prodrugs with a broad molar ratio range could also conserve the synergistic effect of active drugs. More importantly, this prodrug activation platform is versatile and applicable to shift drug identities if encountered multidrug resistance. Therefore, such a platform for EISA directed bioorthogonally activatable prodrug design should be useful in the exploration in chemical space for the discovery of biological probes and medicines for anticancer chemotherapy.

According to the above study, we realized that the overall anticancer efficacy was largely dependent on the decaging reaction rate. The efficient decaging for Dox or PTX generated higher potency than their native drugs while slow decaging for MMAF-OMe or Mytoxin A did not show any enhancement against cancer cells. The decaging reaction kinetics varied by the functional groups, chemical structure, solution $\mathrm{pH}$, etc. The mechanistic study of the decaging reaction ${ }^{35-36}$ as well as new powerful bond-cleaving reactions ${ }^{37}$ would further facilitate the development of bioorthogonal prodrugs. 


\section{Methods}

Activation of prodrug in vitro. $100 \mu \mathrm{L}$ of $1.0 \mu \mathrm{M}$ NapFFYpK-Tz in PBS buffer was mixed with $100 \mu \mathrm{L}$ of $0.5 \mu \mathrm{M}$ TCO caged prodrugs in PBS buffer. The solution was thoroughly mixed and incubated at $37^{\circ} \mathrm{C}$ in the dark. The reaction process was monitored using UPLC-MS/MS analysis.

Accumulation of tetrazine in live cells. Cells at a density of $10^{4}$ cells per well were sequentially incubated with $100 \mu \mathrm{L}$ of 100-500 $\mu \mathrm{M}$ NapFFYpK-Tz, NapFFYK-Tz or NapYpK-Tz for $6 \mathrm{~h}$, rinsed with PBS, then incubated with $100 \mu \mathrm{L}$ of $50 \mu \mathrm{M}$ TCO-CMR for $24 \mathrm{~h}$. The fluorescence intensity of released coumarin was detected using plate reader (ex./em. 380/450 nm).

Location of self-assembly in HeLa cells. HeLa cells were firstly placed in glass chamber and cultured with $2 \mathrm{~mL}$ of culture medium containing $500 \mu \mathrm{M}$ NapFFYpK-Tz for $6 \mathrm{~h}$. Then, cells were rinsed by PBS and incubated with pre-warmed staining solution (500 nM of ER-Tracker ${ }^{\mathrm{TM}}$ Red dyes) for $30 \mathrm{~min}$ at $37^{\circ} \mathrm{C}$. After rinsing the cells by PBS buffer for at least five times, the cell-containing glass chamber was fixed on the confocal microscope stage. $1 \mathrm{~mL}$ of $50 \mu \mathrm{M}$ TCO-CMR (dissolved in PBS buffer) was added to the cells that were subject to fluorescent imaging.

Cell viability. Cell proliferation was assessed by the MTT assay. To measure the cytotoxicity of NapFFYpK-Tz against HeLa cells, HS-5 cells and HcerEpic cells, cells were incubated with $200 \mu \mathrm{L}$ of 100-500 $\mu \mathrm{M}$ NapYpFFK-Tz for $72 \mathrm{~h}$. To measure the cytotoxicity of TCO caged prodrug or active drugs against HeLa cells, HS-5 cells and HcerEpic cells, cells were incubated with $200 \mu \mathrm{L}$ of $0.0001-10 \mu \mathrm{M}$ TCO caged prodrug or active drugs for $72 \mathrm{~h}$. To determine the cytotoxicity of activated drugs against HeLa cells, HS- 5 cells and HcerEpic cells, cells were sequentially incubated with $100 \mu \mathrm{L}$ of $500 \mu \mathrm{M}$ NapFFYpK-Tz for $6 \mathrm{~h}$, rinsed with PBS, then incubated with $200 \mu \mathrm{L}$ of $0.00001-10 \mu \mathrm{M}$ prodrug for $72 \mathrm{~h}$. In the study of drug combination of Dox/PTX and PTX/MMAF-OMe against HeLa cells, HS-5 cells and HcerEpic cells, Dox/PTX and PTX/MMAF-OMe were at a drug ratio of $1: 1$ and 1:100, respectively.

Tumor inhibition experiments. All animal procedures were performed under the supervision and guidance of Animal Care and Use Committee, National Center for Nanoscience and Technology (NCNST). All animal experiments were approved by the Animal Ethics Committee, NCNST. When the tumor volume reached approximately $80-100 \mathrm{~mm}^{3}$, five mice in each group were used for therapeutic studies. Mice in the treatment group received an i.v. injection of $50 \mathrm{mmol} / \mathrm{Kg} \mathrm{NapFFYpK-Tz} \mathrm{and} \mathrm{a} \mathrm{subsequent} 0.3$ $\mathrm{mmol} / \mathrm{Kg}$ TCO-MMAF-OMe after a $2 \mathrm{~h}$ interval. In the control groups, mice were received $50 \mathrm{mmol} / \mathrm{Kg}$ NapFFYpK-Tz, $10 \mathrm{mmol} / \mathrm{Kg}$ TCO-PTX, $10 \mathrm{mmol} / \mathrm{Kg}$ PTX, $0.3 \mathrm{mmol} / \mathrm{Kg} \mathrm{MMAF-OMe,} 0.3 \mathrm{mmol} / \mathrm{Kg}$ TCO-MMAF-OMe, NapFFYpK-Tz-2h-TCO-PTX [i.v. injection of 50 mmol/Kg NapFFYpK-Tz followed by i.v. injection of $10 \mathrm{mmol} / \mathrm{Kg}$ TCO-PTX after a $2 \mathrm{~h}$ interval]. In the group of shift prodrug, mice initially received an i.v. injection of $50 \mathrm{mmol} / \mathrm{Kg} \mathrm{NapFFYpK-Tz} \mathrm{followed} \mathrm{by} \mathrm{i.v.} \mathrm{injection} \mathrm{of} 10 \mathrm{mmol} / \mathrm{Kg}$ TCO-PTX after a $2 \mathrm{~h}$ interval, then $10 \mathrm{mmol} / \mathrm{Kg}$ TCO-PTX was shifted to $0.3 \mathrm{mmol} / \mathrm{Kg}$ TCO-MMAF-OMe after tumor volume reached to $200 \mathrm{~mm}^{3}$. The mice received eight treatment courses on day 0 , day 3 , day 6 , day 9 , day 12 , day 15 , day 18 and day 21 . Tumor size and body weight were measured every two days.

\section{Data availability}

A reporting summary for this article is available as a Supplementary Information file. Data that support the 
findings reported herein are available on reasonable request from the corresponding author.

\section{Acknowledgements}

This work was supported by National Key R\&D Program of China (2017YFA0205901), National Natural Science Foundation of China (21675036, 51873046 to Y. G., 51903064 to Q. Y.), Beijing Natural Science

Foundation (7204286), CAS Pioneer Hundred Talents Program and Key Research Program of Frontier Sciences of the Chinese Academy of Sciences (ZDBS-LY-SLH039) for financial support.

\section{Author contributions}

Q. Y., T. L and Y. G. developed the concept and designed the experiments; Q. Y. and S. G. performed the experiments; all authors analyzed the results and edited the manuscript.

\section{Additional information}

Supplementary Information accompanies this paper at http://www. ${ }^{* \star * \star * \star}$

Competing interests: The authors declare no competing interests.

\section{References}

1. Sharma, P.; Hu-Lieskovan, S.; Wargo, J. A.; Ribas, A., Primary, adaptive, and acquired resistance to cancer immunotherapy. Cell 2017, 168, 707-723.

2. Herbst, R. S.; Morgensztern, D.; Boshoff, C., The biology and management of non-small cell lung cancer. Nature 2018, 553, 446-454.

3. Dagogo-Jack, I.; Shaw, A. T., Tumour heterogeneity and resistance to cancer therapies. Nat. Rev. Clin. Oncol. 2018, 15, 81-94.

4. Harrison, R. K., Phase II and phase III failures: 2013-2015. Nat. Rev. Drug Discov. 2016, 15, 817-818.

5. Kinch, M. S.; Haynesworth, A.; Kinch, S. L.; Hoyer, D., An overview of FDA-approved new molecular entities: 1827-2013. Drug Discov. Today 2014, 19, 1033-1039.

6. Sievers, E. L.; Senter, P. D., Antibody-drug conjugates in cancer therapy. Ann. Rev. Med. 2013, 64, 15-29.

7. Barenholz, Y., Doxil-the first FDA-approved nano-drug: lessons learned. J. Control. Release 2012, 160, 117-134.

8. Desai, N.; Trieu, V.; Yao, Z. W.; Louie, L.; Ci, S.; Yang, A.; Tao, C. L.; De, T.; Beals, B.; Dykes, D.; Noker, P.; Yao, R.; Labao, E.; Hawkins, M.; Soon-Shiong, P., Increased antitumor activity, intratumor paclitaxel concentrations, and endothelial cell transport of cremophor-free, albumin-bound paclitaxel, ABI-007, compared with cremophor-based paclitaxel. Clin. Cancer Res., 2006, 12, 1317-1324.

9. Srinivasarao, M.; Low, P. S., Ligand-targeted drug delivery. Chem. Rev. 2017, 117, 12133-12164.

10. Peer, D.; Karp, J. M.; Hong, S.; FaroKHzad, O. C.; Margalit, R.; Langer, R., Nanocarriers as an emerging platform for cancer therapy. Nat. Nanotech. 2007, 2, 751-760.

11. Sun, Q.; Zhou, Z.; Quu, N.; Shen, Y., Rational design of cancer nanomedicine: nanoproperty integration and synchronization. Adv. Mater. 2017, 29, 1606628. 
12. LeBeau, A. P., Considerations for implementing an informatics system to support biologics drug discovery. Drug Discov. Today 2019, 24, 42-45.

13. Yao, Q.; Lin, F.; Fan, X.; Wang, Y.; Liu, Y.; Liu, Z.; Jiang, X.; Chen, P. R.; Gao, Y., Synergistic enzymatic and bioorthogonal reactions for selective prodrug activation in living systems. Nat. Commun. 2018, 9, 5032.

14. Rossin, R.; Versteegen, R. M.; Wu, J.; Khasanov, A.; Wessels, H. J.; Steenbergen, E. J.; ten Hoeve, W.; Janssen, H. M.; van Onzen, A. H. A. M.; Hudson, P. J.; Robillard, M. S., Chemically triggered drug release from an antibody-drug conjugate leads to potent antitumour activity in mice. Nat. Commun. 2018, 9, 1484.

15. Miller, M. A.; Askevold, B.; Mikula, H.; Kohler, R. H.; Pirovich, D.; Weissleder, R., Nano-palladium is a cellular catalyst for in vivo chemistry. Nat. Commun. 2017, 8, 15906.

16. Mejia Oneto J. M., Khan I., Seebald L., Royzen M. In vivo bioorthogonal chemistry enables local hydrogel and systemic pro-drug to treat soft tissue sarcoma. ACS Central Sci. 2016, 2, 476-482.

17. Zheng, Y.; Ji, X.; Yu, B.; Ji, K.; Gallo, D.; Csizmadia, E.; Zhu, M.; Choudhury, M. R.; De La Cruz, L. K. C.; Chittavong, V.; Pan, Z.; Yuan, Z.; Otterbein, L. E.; Wang, B., Enrichment-triggered prodrug activation demonstrated through mitochondria-targeted delivery of doxorubicin and carbon monoxide. Nat. Chem. 2018, 10, 787-794.

18. Lin, A.; Giuliano, C. J.; Palladino, A.; John, K. M.; Abramowicz, C.; Yuan, M. L.; Sausville, E. L.; Lukow, D. A.; Liu, L. W.; Chait, A. R.; Galluzzo, Z. C.; Tucker, C.; Sheltzer, J. M., Off-target toxicity is a common mechanism of action of cancer drugs undergoing clinical trials. Sci. Transl. Med. 2019, 11, eaaw8412.

19. Miller, M. A.; Mikula, H.; Luthria, G.; Li, R.; Kronister, S.; Prytyskach, M.; Kohler, R. H.; Mitchison, T.; Weissleder, R., Modular nanoparticulate prodrug design enables efficient treatment of solid tumors using bioorthogonal activation. ACS Nano 2018, 12, 12814-12826.

20. Versteegen, R. M.; Ten Hoeve, W.; Rossin, R.; de Geus, M. A. R.; Janssen, H. M.; Robillard, M. S., Click-to-Release from trans-cyclooctenes: Mechanistic insights and expansion of scope from established carbamate to remarkable ether cleavage. Angew. Chem. Int. Ed. 2018, 57, 10494-10499.

21. Wells, J. A.; McClendon, C. L., Reaching for high-hanging fruit in drug discovery at protein-protein interfaces. Nature 2017, 450, 1001-1009.

22. Lipinski, C. A.; Lombardo, F.; Dominy, B. W.; Feeney, P. J., Experimental and computational approaches to estimate solubility and permeability in drug discovery and development settings. $A d v$. Drug Deliv. Rev. 1997, 23, 3-25.

23. Jarvis, B. B.; Comezoglu, F. T.; Lee, Y. W.; Flippenanderson, J. L.; Gilardi, R. D.; George, C. F., Novel macrocyclic trichothecenes from myrothecium roridum. B. Soc. Chim. Belg. 1986, 95, 681-697.

24. He, H. J.; Wang, H. M.; Feng, Z. Q. Q.; Kim, B.; Yang, D.; Wang, J. Q.; Shy, A.; Xu, B., Enzymatic noncovalent synthesis. Chem. Rev. 2020, doi: 10.1021/acs.chemrev.0c00306.

25. He, H. J.; Wang, J. Q.; Wang, H. M.; Zhou, N.; Yang, D.; Green, D. R.; Xu, B., Enzymatic Cleavage of branched peptides for targeting mitochondria. J. Am. Chem. Soc. 2018, 140, 1215-1218. 
26. Zhou, J.; Du, X. W.; Yamagata, N.; Xu, B., Enzyme-instructed self-assembly of small D-peptides as a multiple-step process for selectively killing cancer cells. J. Am. Chem. Soc. 2016, 138, 3813-3823.

27. Zhou, J.; Du, X. W.; Li, J.; Yamagata, N.; Xu, B., Taurine boosts cellular uptake of small D-peptides for enzyme-instructed intracellular molecular self-assembly. J. Am. Chem. Soc. 2015, 137, 10040-10043.

28. Lipinski, C.; Hopkins, A., Navigating chemical space for biology and medicine. Nature 2004, 432, 855-861.

29. Versteegen, R. M.; Rossin, R.; ten Hoeve, W.; Janssen, H. M.; Robillard, M. S., Click to release: instantaneous doxorubicin elimination upon tetrazine ligation. Angew. Chem. Int. Ed. 2013, 52, 14112-14116.

30. Fan, X. Y.; Ge, Y.; Lin, F.; Yang, Y.; Zhang, G.; Ngai, W. S. C.; Lin, Z.; Zheng, S. Q.; Wang, J.; Zhao, J. Y.; Li, J.; Chen, P. R., Optimized tetrazine derivatives for rapid bioorthogonal decaging in living cells. Angew. Chem. Int. Ed. 2016, 55, 14046-14050.

31. Kuang, Y.; Shi, J.; Li, J.; Yuan, D.; Alberti, K. A.; Xu, Q.; Xu, B., Pericellular hydrogel/nanonets inhibit cancer cells. Angew. Chem. Int. Ed. 2014, 53, 8104-8107.

32. Yao, Q.; Huang, Z.; Liu, D.; Chen, J.; Gao, Y., Enzyme-instructed supramolecular self-assembly with anticancer activity. Adv. Mater. 2019, 31, e1804814.

33. van der Meel, R.; Sulheim, E.; Shi, Y.; Kiessling, F.; Mulder, W. J. M.; Lammers, T., Smart cancer nanomedicine. Nat. Nanotech. 2019, 14, 1007-1017.

34. Chou, T. C., Drug combination studies and their synergy quantification using the Chou-Talalay method. Cancer Res. 2010, 70, 440-446.

35. Carlson, J. C. T.; Mikula, H.; Weissleder, R., Unraveling tetrazine-triggered bioorthogonal elimination enables chemical tools for ultrafast release and universal cleavage. J. Am. Chem. Soc. 2018, 140, 3603-3612.

36. Ravasco, J. M. J. M.; Coelho, J. A. S., Predictive multivariate models for bioorthogonal inverse-electron demand Diels-Alder reactions. J. Am. Chem. Soc. 2020, 142, 4235-4241.

37. Kim, J.; Bertozzi, C. R., A bioorthogonal reaction of N-Oxide and boron reagents. Angew. Chem. Int. Ed. 2015, 54, 15777-15781. 


\section{Supplementary Information}

\section{Enzymatic non-covalent synthesis of a versatile platform for bioorthogonal prodrugs activation to combat drug resistance}

Qingxin Yao, ${ }^{1,3}$ Shuo Gao, ${ }^{2}$ Chengling Wu, ${ }^{1}$ Ting Lin ${ }^{2, *}$ and Yuan Gao ${ }^{1,3,{ }^{*}}$

${ }^{1}$ CAS Center for Excellence in Nanoscience, CAS Key Laboratory of Biomedical Effects of Nanomaterials and Nanosafety, National Center for Nanoscience and Technology, Beijing 100190, China;

${ }^{2}$ Fujian Provincial Key Laboratory of Innovative Drug Target Research, School of Pharmaceutical Sciences, Xiamen University, Xiamen 361102, China;

${ }^{3}$ University of Chinese Academy of Sciences, Beijing 100049, China.

"E-mail: gaoy@nanoctr.cn; linting@xmu.edu.cn

Table of contents

1. General methods

2. Chemical extraction and synthesis

3. Supplementary methods

4. Supplementary figures

5. Supplementary spectra

6. References 


\section{General methods}

All chemical reagents and solvents were used as receiving from commercial sources without further purification unless otherwise stated. 2-Cl-trityl chloride resin (1.0-1.2 mmol/g) and Fmoc-amino acids were obtained from GL Biochem (Shanghai) Co., Ltd. Doxorubicin hydrochloride (Dox $\cdot \mathrm{HCl}$ ) and paclitaxel (PTX) were bought from Tokyo Kasei Kogyo Co., Ltd. Monomethyl auristatin F methyl ester (MMAF-OMe) was bought from MedChemexpress Co., Ltd. Mytoxin A was the extract of potato dextrose agar cultured fungus A-S-4. NMR spectra were recorded on a Bruker $400 \mathrm{MHz}$ Fourier transform spectrometer. High-resolution ESI mass spectra (HRMS) were recorded on a Q-Exactive LC-MS/MS mass spectrometer. TEM images were obtained on a Tecnai G2 20 S-TWIN transmission electron microscope. UPLC-MS/MS analyses were performed using a Triple Quadrupole Liquid Chromatograph Mass Spectrometer (LCMS 8050, Shimadzu) in multiple reaction-monitoring mode (MRM). Cell imaging was obtained from LSM 700 laser scanning confocal microscope (Zeiss). 


\section{Chemical extraction and synthesis}

\subsection{Extraction and isolation of Mytoxin A}

The fungus A-S- 4 was cultured with $5 \mathrm{~L}$ potato dextrose agar (PDA) media (prepared from peeled and sliced potato $200 \mathrm{~g}$, glucose $20 \mathrm{~g}$ and agar $20 \mathrm{~g}$ in $1000 \mathrm{~mL}$ water) at $28{ }^{\circ} \mathrm{C}$ for 16 days. After fermentation, mycelium and media were cut into small pieces and soak extracted with mixed solvent EtOAc-MeOH (4:1) at room temperature overnight. The extract solution was filtered with gauze and evaporated under reduced pressure at $35^{\circ} \mathrm{C}$ to give a crude extract $(4.1 \mathrm{~g})$.

The crude extract was subjected to ODS column chromatography with a gradient of $\mathrm{MeOH}-\mathrm{H}_{2} \mathrm{O}(0: 100$; $30: 70 ; 50: 50 ; 70: 30 ; 100: 0, \mathrm{v} / \mathrm{v}$ ) to give eighteen fractions (Fr. 1-18). Fraction 11 (74.5 mg) was chromatographed on Sephadex LH-20 and eluted with methanol to give two fractions (Fr. 11-a 26 mg, Fr. 11-b $43 \mathrm{mg}$ ). Fr. 11-b (43 mg) was isolated and purified by Prep-HPLC with $\mathrm{MeOH}-\mathrm{H}_{2} \mathrm{O}(55: 45, \mathrm{v} / \mathrm{v}$ ) to obtain Mytoxin A (17.4 mg) as white power. The molecular structure of Mytoxin $A$ is as follows:

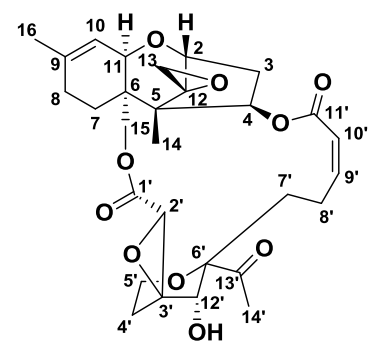

${ }^{1} \mathrm{H}$ NMR $\left(\mathrm{CDCl}_{3}, 600 \mathrm{MHz}\right) \delta(\mathrm{ppm}): 6.46(1 \mathrm{H}, \mathrm{ddd}, \mathrm{J}=7.5,9.2,11.5 \mathrm{~Hz}, \mathrm{H}-9$ ') $5.94(1 \mathrm{H}, \mathrm{dd}, \mathrm{J}=4.6,8.5$ $\mathrm{Hz}, \mathrm{H}-4), 5.87(1 \mathrm{H}, \mathrm{dd}, \mathrm{J}=1.8,11.6 \mathrm{~Hz}, \mathrm{H}-10$ '), $5.42(1 \mathrm{H}, \mathrm{d}, \mathrm{J}=5.0 \mathrm{~Hz}, \mathrm{H}-10), 4.56(1 \mathrm{H}, \mathrm{d}, \mathrm{J}=12.3 \mathrm{~Hz}$, H-15A), $4.06(1 \mathrm{H}, \mathrm{d}, \mathrm{J}=12.3 \mathrm{~Hz}, \mathrm{H}-15 \mathrm{~B}), 4.05(2 \mathrm{H}, \mathrm{d}, \mathrm{J}=9.5 \mathrm{~Hz}, \mathrm{H}-5$ '), $3.85(1 \mathrm{H}, \mathrm{d}, \mathrm{J}=4.9 \mathrm{~Hz}, \mathrm{H}-2), 3.56$ $(1 \mathrm{H}, \mathrm{d}, \mathrm{J}=5.1 \mathrm{~Hz}, \mathrm{H}-11), 3.44\left(1 \mathrm{H}, \mathrm{s}, \mathrm{H}-2^{\prime}\right), 3.25\left(1 \mathrm{H}, \mathrm{s}, \mathrm{H}-12{ }^{\prime}\right), 3.14(1 \mathrm{H}, \mathrm{d}, \mathrm{J}=4.0 \mathrm{~Hz}, \mathrm{H}-13 \mathrm{~A}), 3.05(1 \mathrm{H}$, m, H-8'A), 2.81 (1H, d, J = 4.0 Hz, H-13B), 2.58 (1H, m, H-4'A), 2.36 (1H, m, H-7'A), 2.31 (3H, s, H-14'), $2.19(1 \mathrm{H}, \mathrm{m}, \mathrm{H}-3 \mathrm{~B}), 1.73$ (3H, s, H-16), 1.69-2.04 (6H, m, H's-7, 8, 4'B, 3A), 1.69 (1H, m, H-7'B), 1.59 (1H, m, $\mathrm{H}-8$ 'B), 0.81 (3H, s, H-14).

${ }^{13} \mathrm{C} \mathrm{NMR}\left(\mathrm{CDCl}_{3}, 150 \mathrm{MHz}\right) \delta(\mathrm{ppm}): 212.7$ (C-13'), 166.9 (C-11'), 166.7 (C-1'), 149.9 (C-9'), 140.8 (C-9), 121.0 (C-10'), 118.5 (C-10), 87.4 (C-6'), 79.3 (C-2), 75.4 (C-12'), 73.1 (C-4), 67.5 (C-11), 65.4 (C-12), 64.7 (C-15), 64.1 (C-3'), 60.6 (C-5'), 59.0 (C-2'), 49.8 (C-5), 48.0 (C-13), 43.4 (C-6), 34.7 (C-3), 29.0 (C-14'), 27.6 (C-8), 26.7 (C-8'), 23.5 (C-16), 22.8 (C-4'), 22.5 (C-7'), 20.1 (C-7), 8.2 (C-14).

\subsection{Synthesis of prodrugs}

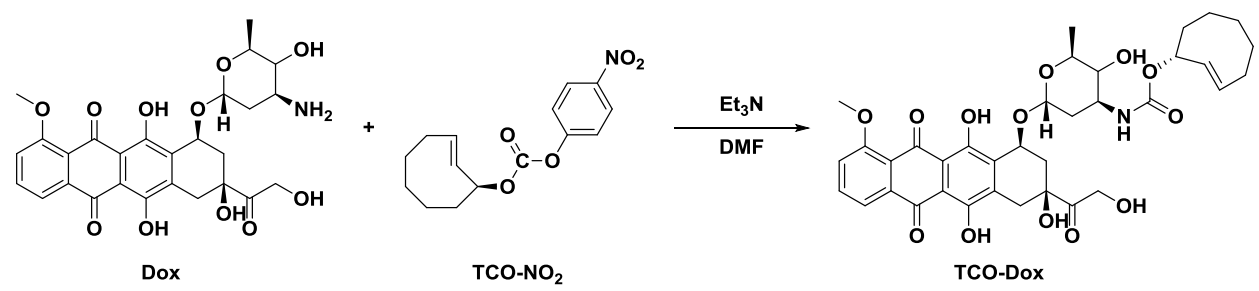

The synthetic route and molecular structure of TCO-Dox were shown above. Axial-(E)-cyclooct-2-enol (TCO), axial-(E)-cyclooct-2-en-1-yl doxorubicin carbamate (TCO-NO 
doxorubicin carbamate (TCO-Dox) were prepared according to our previous report ${ }^{1}$. HRMS (m/z): calcd. for $\mathrm{C}_{36} \mathrm{H}_{41} \mathrm{NO}_{13}, 695.26$; Found $[\mathrm{M}+\mathrm{H}]^{+}$: 696.26508.
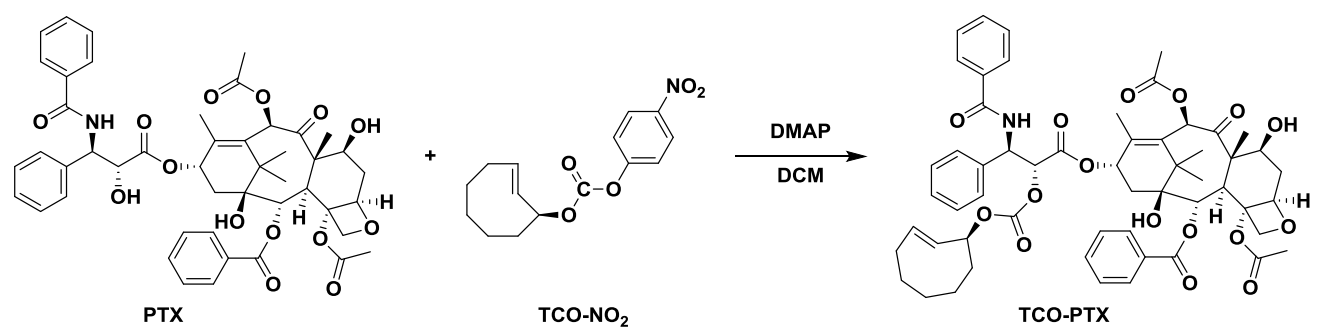

The synthetic route and molecular structure of TCO-PTX were shown above. To a solution of PTX (117.3 $\mathrm{mg}, 137.4 \mu \mathrm{mol})$ in $1 \mathrm{~mL}$ of anhydrous DCM was added TCO-NO $2(20.0 \mathrm{mg}, 68.7 \mu \mathrm{mol})$ and DMAP $(1.0$ $\mathrm{mg}, 8.2 \mu \mathrm{mol})$. The mixture was stirred in the dark at $30^{\circ} \mathrm{C}$ for one day. The solvent was removed under reduced pressure and the residue was purified by column chromatography (Hexane:EtOAc=1:1) to give TCO-PTX (59.5 mg, 86.1\%). HRMS (m/z): calcd. for $\mathrm{C}_{56} \mathrm{H}_{63} \mathrm{NO}_{16}, 1005.41$; found $[\mathrm{M}+\mathrm{H}]^{+}: 1006.42231$.

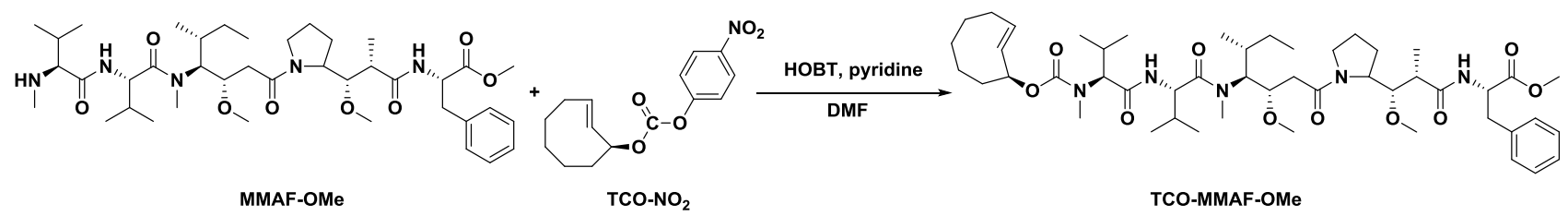

The synthetic route and molecular structure of TCO-MMAF-OMe were shown above. To a solution of MMAF-OMe (37.3 mg, $50 \mu \mathrm{mol})$ in $0.5 \mathrm{~mL}$ of anhydrous DMF was added TCO-NO $2(20.0 \mathrm{mg}, 68.7 \mu \mathrm{mol})$, HOBT $(1.0 \mathrm{mg}, 7.4 \mu \mathrm{mol})$ and pyridine $(50 \mu \mathrm{L})$. The mixture was stirred in the dark at $30^{\circ} \mathrm{C}$ for three days. The crude material was purified by semi-preparative HPLC to give TCO-MMAF-OMe $(23.1 \mathrm{mg}, 51.1 \%)$. HRMS (m/z): calcd. for $\mathrm{C}_{49} \mathrm{H}_{79} \mathrm{~N}_{5} \mathrm{O}_{10}$, 897.58; found [M+Na] ${ }^{+}: 920.57166$.

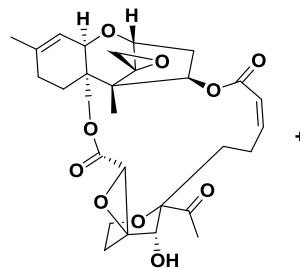

Mytoxin A
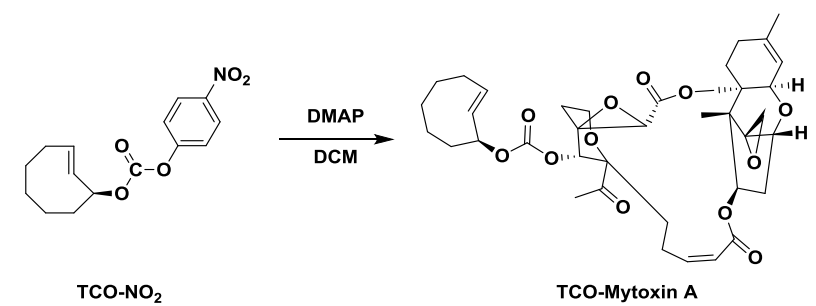

The synthetic route and molecular structure of TCO-Mytoxin A were shown above. To a solution of Mytoxin A (15.0 mg, $30.0 \mu \mathrm{mol})$ in $1 \mathrm{~mL}$ of anhydrous DCM was added TCO-NO $2(20.0 \mathrm{mg}, 68.7 \mu \mathrm{mol})$ and DMAP $(1.0 \mathrm{mg}, 8.2 \mu \mathrm{mol})$. The mixture was stirred in the dark at $30^{\circ} \mathrm{C}$ for one day. The solvent was removed under reduced pressure and the residue was purified by column chromatography (Hexane:EtOAc=1:1) to give TCO-Mytoxin A (3.3 mg, 15.8\%). HRMS (m/z): calcd. for $\mathrm{C}_{38} \mathrm{H}_{48} \mathrm{NO}_{12}, 696.31$; found $[\mathrm{M}+\mathrm{Na}]^{+}: 719.30406$.

\subsection{Synthesis of peptides}



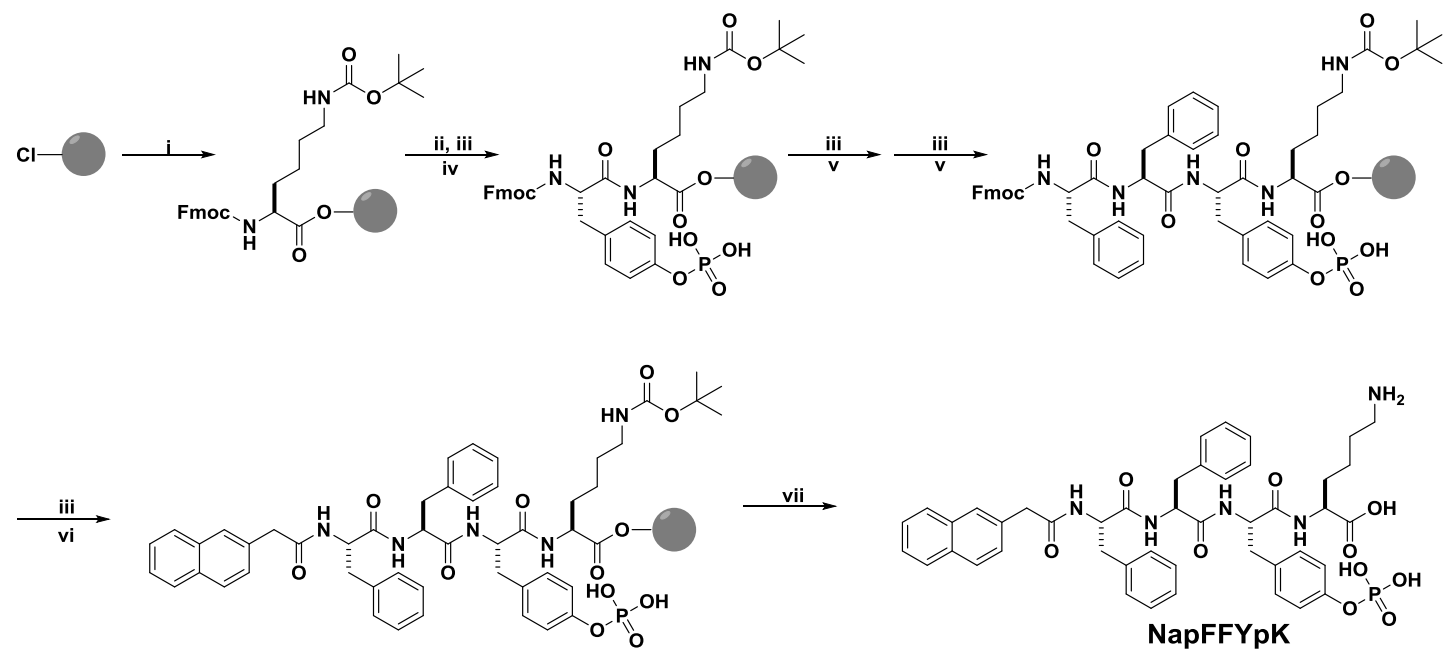

i) Fmoc-L-Lys(Boc)-OH, DIPEA, DMF; ii) DCM:MeOH:DIPEA=80:15:5 (v/v); iii) 20\% piperidine / DMF (v/v);

iv) Fmoc-L-Tyr $\left(\mathrm{PO}_{3} \mathrm{H}_{2}\right)$-OH, HBTU, DIPEA, DMF; v) Fmoc-L-Phe-OH, HBTU, DIPEA, DMF;

vi) 2-Naphthylacetic acid, HBTU, DIPEA, DMF; vii) TFA.

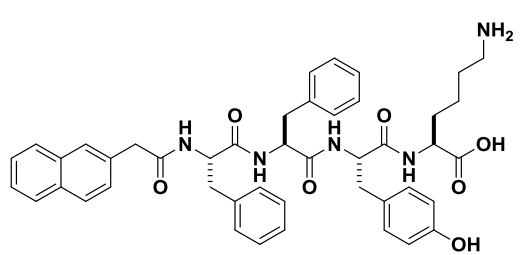

NapFFYK

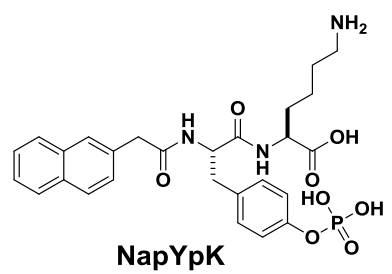

NapYpK

NapFFYpK was synthesized via a typical solid phase peptide synthesis (SPPS) using 2-chlorotrity resin and the corresponding Fmoc-protected amino acids. The synthetic route and molecular structure of NapFFYpK were shown above. The product was purified by semi-preparative HPLC to give white powder. ${ }^{1} \mathrm{H}$ NMR (DMSO-d6, $\left.400 \mathrm{MHz}\right) \delta$ (ppm): 8.349-7.997 (m, 4H), 7.994-7.650 (m, 6H), 7.595-7.395 (m, $3 \mathrm{H}), 7.319-6.929(\mathrm{~m}, 12 \mathrm{H}), 4.672-4.432 \quad(\mathrm{~m}, 3 \mathrm{H}), 4.170-4.056 \quad(\mathrm{~m}, 1 \mathrm{H}), 3.612-3.436 \quad(\mathrm{q}$, $2 \mathrm{H}), 3.062-2.610(\mathrm{~m}, 8 \mathrm{H}), 1.771-1.409(\mathrm{~m}, 4 \mathrm{H}), 1.319-1.119(\mathrm{~m}, 2 \mathrm{H})$. ESI-MS $(\mathrm{m} / \mathrm{z})$ : calcd. for $\mathrm{C}_{45} \mathrm{H}_{50} \mathrm{~N}_{5} \mathrm{O}_{10} \mathrm{P}, 851.33$; found $[\mathrm{M}-\mathrm{H}]^{-}, 850.30$.

NapFFYK was synthesized similarly to NapFFYpK. ${ }^{1} \mathrm{H}$ NMR (DMSO- $\left.d 6,400 \mathrm{MHz}\right) \delta$ (ppm): 8.538-8.208 $(\mathrm{m}, 3 \mathrm{H}), 7.840-7.631(\mathrm{~m}, 3 \mathrm{H}), 7.578-7.333(\mathrm{~m}, 4 \mathrm{H}), 7.222-6.973(\mathrm{~m}, 12 \mathrm{H}), 6.680-6.547(\mathrm{~d}, 2 \mathrm{H})$, 4.555-4.293 (m, 3H), 3.874-3.776 (m, 1H), 3.597-3.396 (q, 2H), 3.053-2.601 (m, 7H), 1.712-1.069 (m, $6 \mathrm{H})$. ESI-MS (m/z): calcd. for $\mathrm{C}_{45} \mathrm{H}_{49} \mathrm{~N}_{5} \mathrm{O}_{7}, 771.36$; found $[\mathrm{M}+\mathrm{H}]^{+}, 772.30$.

NapYpK was synthesized similarly to NapFFYpK. ${ }^{1} \mathrm{H}$ NMR (DMSO- $d 6,400 \mathrm{MHz}$ ) $\delta$ (ppm): 8.641-8.171 $(\mathrm{m}, 2 \mathrm{H}), \quad 7.877-7.614(\mathrm{~m}, 4 \mathrm{H}), 7.447-7.253(\mathrm{~m}, 3 \mathrm{H}), 7.120-6.704(\mathrm{~m}, 4 \mathrm{H}), 4.604-4.365(\mathrm{~m}$, $1 \mathrm{H})$, 4.027-3.827 $(\mathrm{m}, 1 \mathrm{H}), 3.741-3.400(\mathrm{q}, 2 \mathrm{H}), 3.023-2.607(\mathrm{~m}, 2 \mathrm{H}), 1.604-0.969(\mathrm{~m}, 6 \mathrm{H})$. ESI-MS (m/z): calcd. for $\mathrm{C}_{27} \mathrm{H}_{32} \mathrm{~N}_{3} \mathrm{O}_{8} \mathrm{P}, 557.19$; found $[\mathrm{M}+\mathrm{H}]^{+}$, 558.10. 


\subsection{Synthesis of peptide-Tz}

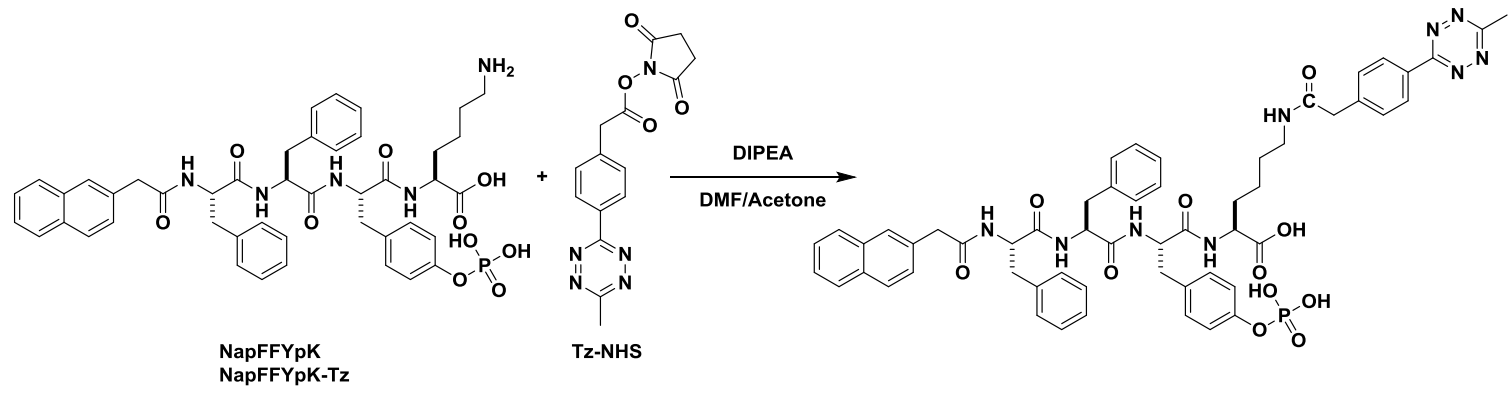

The synthetic route and molecular structure of NapFFYpK-Tz were shown above. 2-(4-(6-methyl-1,2,4,5-tetrazin-3-yl)phenyl) acetic acid (Tz-COOH, Tz) ${ }^{2}$ and 2,5-dioxopyrrolidin-1-yl 2-(4-(6-methyl-1,2,4,5-tetrazin-3-yl)phenyl) acetate (Tz-NHS) was prepared according to our previous report ${ }^{1}$. NapFFYpK (42.6 mg, $0.05 \mathrm{mmol}$ ) was dissolved in $1 \mathrm{~mL}$ of DMF and DIPEA (11.35 mg, 0.088 mmol) was added to obtain a well-dispersed solution. Tz-NHS (16.4 mg, $0.05 \mathrm{mmol})$ dissolved in $1 \mathrm{~mL}$ of acetone was added into the peptide-containing solution dropwise. The mixture was stirred at room temperature for $24 \mathrm{~h}$ and then subjected to semi-preparative HPLC purification to give the light purple powder (38.5 mg, 72.4\%). ${ }^{1} \mathrm{H}$ NMR (DMSO-d6, $\left.400 \mathrm{MHz}\right) \delta$ (ppm): 8.433-8.330 (d, 2H), 8.330-8.193 (m, $2 \mathrm{H}), 8.193-8.062(\mathrm{~m}, 3 \mathrm{H}), 7.868-7.813(\mathrm{~d}, 1 \mathrm{H}), 7.793-7.695(\mathrm{t}, 2 \mathrm{H}), 7.590-7.391(\mathrm{~m}, 5 \mathrm{H}), 7.276-7.010$ $(\mathrm{m}, 14 \mathrm{H}), 4.627-4.450(\mathrm{~m}, 3 \mathrm{H}), 4.230-4.145(\mathrm{~m}, 1 \mathrm{H}), 3.695-3.424(\mathrm{~m}, 4 \mathrm{H}), 3.104-2.901(\mathrm{~m}$, $8 \mathrm{H}), 2.852-2.637(\mathrm{~m}, 4 \mathrm{H}), 1.783-1.557(\mathrm{~m}, 2 \mathrm{H}), 1.492-1.286(\mathrm{~m}, 4 \mathrm{H}) ; \mathrm{HRMS}(\mathrm{m} / \mathrm{z})$ : calcd. for $\mathrm{C}_{56} \mathrm{H}_{58} \mathrm{~N}_{9} \mathrm{O}_{11} \mathrm{P}, 1063.40$; found [M-H]- 1062.39155.

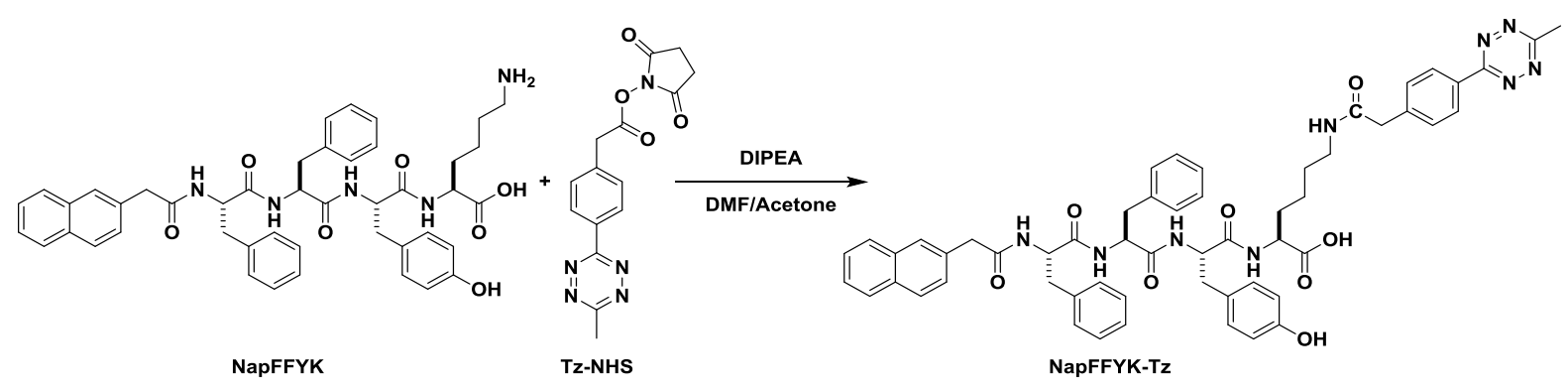

The synthetic route and molecular structure of NapFFYK-Tz were shown above. NapFFYK (38.6 mg, 0.05 mmol) was dissolved in $2 \mathrm{~mL}$ of DMF and DIPEA (11.35 mg, $0.088 \mathrm{mmol}$ ) was added to obtain a well-dispersed solution. Tz-NHS (16.4 mg, $0.05 \mathrm{mmol}$ ) dissolved in $1 \mathrm{~mL}$ of acetone was added into the peptide-containing solution dropwise. The mixture was stirred at room temperature for $24 \mathrm{~h}$ and then subjected to semi-preparative HPLC purification to give the light purple powder $(25.2 \mathrm{mg}, 51.3 \%) .{ }^{1} \mathrm{H}$ NMR (DMSO-d6, $400 \mathrm{MHz}) \delta(\mathrm{ppm}):$ 8.416-8.358 (d, 2H), 8.275-8.012 (m, 5H), 7.868-7.814 (d, $1 \mathrm{H})$, 7.798-7.697 (t, $2 \mathrm{H})$, 7.618-7.397 (m, 5H), 7.195-7.016 (m, 12H), 6.699-6.581 (d, 2H), 4.594-4.436 (m, $3 \mathrm{H}), \quad 4.234-4.145(\mathrm{~m}, \quad 1 \mathrm{H}), \quad 3.606-3.469(\mathrm{~m}, 4 \mathrm{H}), \quad 3.116-2.864(\mathrm{~m}, \quad 8 \mathrm{H}), 2.795-2.642(\mathrm{~m}$, $3 \mathrm{H}), 1.812-1.531(\mathrm{~m}, 2 \mathrm{H}), 1.463-1.276(\mathrm{~m}, 4 \mathrm{H})$; HRMS $(\mathrm{m} / \mathrm{z})$ : calcd. for $\mathrm{C}_{56} \mathrm{H}_{57} \mathrm{~N}_{9} \mathrm{O}_{8}$, 983.43; found $[\mathrm{M}+\mathrm{Na}]^{+}, 1006.42259$. 


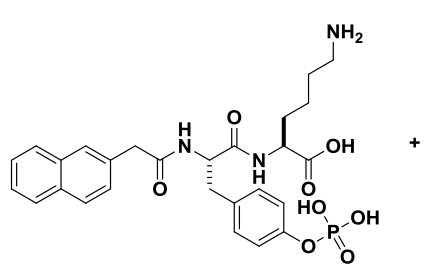

NapYpK
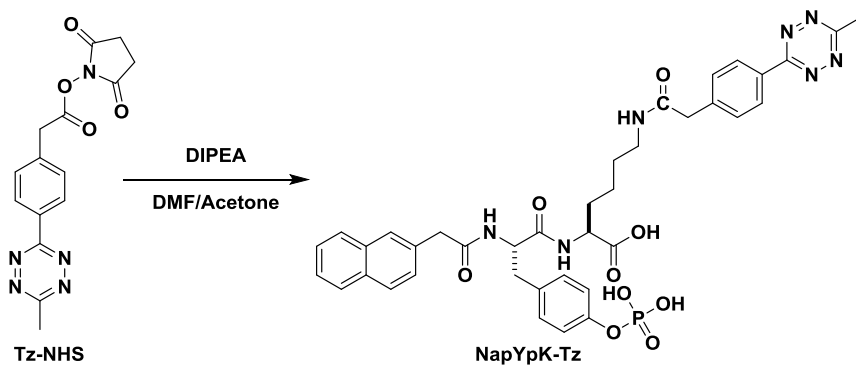

The synthetic route and molecular structure of NapYpK-Tz were shown above. NapYpK (27.8 mg, 0.05 mmol) was dissolved in $1 \mathrm{~mL}$ of DMF and DIPEA (11.35 mg, $0.088 \mathrm{mmol}$ ) was added to obtain a well-dispersed solution. Tz-NHS (16.4 mg, $0.05 \mathrm{mmol}$ ) dissolved in $1 \mathrm{~mL}$ of acetone was added into the peptide-containing solution dropwise. The mixture was stirred at room temperature for $24 \mathrm{~h}$ and then subjected to semi-preparative HPLC purification to give the light purple powder (31.5 mg, 82\%). ${ }^{1} \mathrm{H}$ NMR (DMSO-d6, $400 \mathrm{MHz}) \delta(\mathrm{ppm}): 8.440-8.361$ (d, 2H), 8.361-8.246 (t, 2H), 8.160-8.069 (q, 1H), 7.883-7.811 (d, $1 \mathrm{H}), 7.811-7.732(\mathrm{~m}, 2 \mathrm{H}), 7.667-7.590(\mathrm{~s}, 1 \mathrm{H}), 7.562-7.390(\mathrm{~m}, 4 \mathrm{H}), 7.262-7.178(\mathrm{~m}$, $3 \mathrm{H})$, 7.087-6.982 $(\mathrm{m}, 2 \mathrm{H}), 4.639-4.572(\mathrm{~m}, 1 \mathrm{H}), 4.222-4.127(\mathrm{~m}, 1 \mathrm{H}), 3.639-3.463(\mathrm{~m}, 4 \mathrm{H})$, 3.085-2.907 (m, 6H), 2.811-2.706 (m, 1H), 1.774-1.512 (m, 2H), 1.444-1.256 (m, 4H); HRMS (m/z): calcd. for $\mathrm{C}_{38} \mathrm{H}_{40} \mathrm{~N}_{7} \mathrm{O}_{9} \mathrm{P}, 969.26$; found [M-H]', 968.25541. 


\section{Supplementary methods}

\subsection{Preparation of hydrogel}

(1) Hydrogel of NapFFYpK-Tz and NapYpK-Tz. By adding $10 \mathrm{U} / \mathrm{mL}$ of alkaline phosphatase (ALP) into solutions of $0.25-2.0 \mathrm{mg} / \mathrm{mL}$ of NapFFYpK-Tz in PBS buffer, transparent and stable hydrogels were formed at $0.5-2.0 \mathrm{mg} / \mathrm{mL}$.

(2) Hydrogel of NapFFYK-Tz. By adjusting the solution $\mathrm{pH}$ of $2.0 \mathrm{mg} / \mathrm{mL}$ of NapFFYK-Tz to 6.5 in PBS buffer, purple and stable hydrogels were formed.

(3) Precipitate of NapYpK-Tz. By adding $10 \mathrm{U} / \mathrm{mL}$ of alkaline phosphatase (ALP) into solutions of 2.0-10.0 mg/mL of NapYpK-Tz in PBS buffer, precipitates were formed.

\subsection{Activation of prodrug in vitro}

$100 \mu \mathrm{L}$ of $1.0 \mu \mathrm{M}$ NapFFYpK-Tz in PBS buffer was mixed with $100 \mu \mathrm{L}$ of $0.5 \mu \mathrm{M}$ TCO caged prodrugs in PBS buffer. The solution was thoroughly mixed and incubated at $37{ }^{\circ} \mathrm{C}$ in the dark. After different time intervals, $10 \mu \mathrm{L}$ of samples was analyzed using UPLC-MS/MS.

\subsection{Accumulation of $\mathrm{Tz}$ in cells}

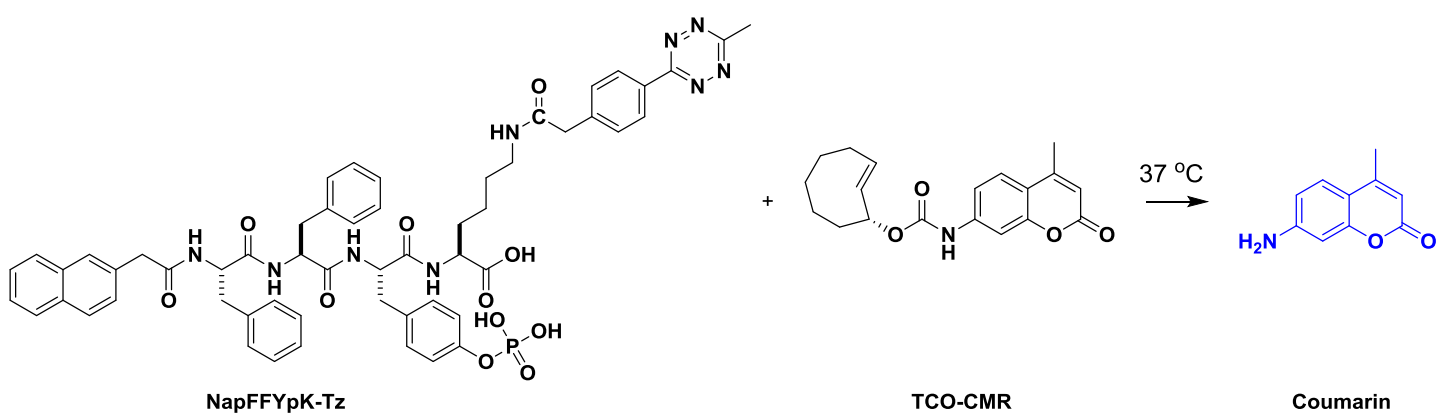

The accumulation of $\mathrm{Tz}$ in cells was determined by the restoration of fluorescence of coumarin according to the reported procedure ${ }^{2}$. Cells at a density of $10^{4}$ cells per well were sequentially incubated with $100 \mu \mathrm{L}$ of 100-500 $\mu \mathrm{M}$ NapFFYpK-Tz, NapFFYK-Tz or NapYpK-Tz for $6 \mathrm{~h}$, rinsed with PBS, then incubated with $100 \mu \mathrm{L}$ of $50 \mu \mathrm{M}$ TCO-CMR ${ }^{2}$ for $24 \mathrm{~h}$. The fluorescence intensity of released coumarin was detected using plate reader (ex./em.380/450 nm).

\subsection{Location of self-assembly in HeLa cells}

HeLa cells were firstly placed in glass chamber and cultured with $2 \mathrm{~mL}$ of culture medium containing 500 $\mu \mathrm{M}$ NapFFYpK-Tz for $6 \mathrm{~h}$. Then, cells were rinsed by PBS and incubated with pre-warmed staining solution ( $500 \mathrm{nM}$ of ER-Tracker ${ }^{\mathrm{TM}}$ Red dyes) for $30 \mathrm{~min}$ at $37^{\circ} \mathrm{C}$. After rinsing the cells by PBS buffer for at least five times, the cell-containing glass chamber was fixed on the confocal microscope stage. $1 \mathrm{~mL}$ of 50 $\mu \mathrm{M}$ TCO-CMR (dissolved in PBS buffer) was added to the cells that were subject to fluorescent imaging.

\subsection{Cell viability}

Cells were plated in flat-bottom 96 -well plates at a density of $5 \times 10^{3}$ cells per well. After cell attachment, 
the cell culture medium was replaced with $200 \mu \mathrm{L}$ of pre-warmed media containing the compounds at different concentrations. After $72 \mathrm{~h}$ of incubation, cell proliferation was assessed by the MTT assay. A fresh mixture of $10 \mu \mathrm{L}$ of thiazolyl blue tetrazolium bromide (MTT) and $90 \mu \mathrm{L}$ of medium were freshly added to each well. After incubation for $4 \mathrm{~h}$, the medium was gently removed. The formazan crystals that formed were dissolved in $110 \mu \mathrm{L}$ of DMSO, and the absorbance was subsequently measured with a plate reader (Perkin Elmer) at $490 \mathrm{~nm}$. $\mathrm{EC}_{50}$ values were calculated using Origin software.

To measure the cytotoxicity of NapFFYpK-Tz against HeLa cells, HS-5 cells and HcerEpic cells, cells were incubated with $200 \mu \mathrm{L}$ of $100-500 \mu \mathrm{M}$ of NapYpFFK-Tz for $72 \mathrm{~h}$, and then cell viability was determined. To measure the cytotoxicity of TCO caged prodrug or native drugs against HeLa cells, HS- 5 cells and HcerEpic cells, cells were incubated with $200 \mu \mathrm{L}$ of $0.0001-10 \mu \mathrm{M}$ TCO caged prodrug or active drugs for $72 \mathrm{~h}$, and then cell viability was determined. To determine the cytotoxicity of activated drugs against HeLa cells, HS-5 cells and HcerEpic cells, cells were sequentially incubated with $100 \mu \mathrm{L}$ of 500 $\mu \mathrm{M}$ NapFFYpK-Tz for $6 \mathrm{~h}$, rinsed with PBS, then incubated with $200 \mu \mathrm{L}$ of 0.00001-10 $\mu \mathrm{M}$ prodrug for $72 \mathrm{~h}$, and finally cell viability was determined. To determine the cytotoxicity of drug combination of Dox/PTX and PTX/MMAF-OMe against HeLa cells, HS-5 cells and HcerEpic cells, Dox/PTX and PTX/MMAF-OMe were at a drug ratio of $1: 1$ and $1: 100$, respectively.

\subsection{UPLC-MS/MS analyses}

UPLC-MS/MS metabolomic analyses were performed using a Triple Quadrupole Liquid Chromatograph Mass Spectrometer (LCMS 8050, Shimadzu) in multiple reaction-monitoring mode (MRM). Data acquisition and processing were performed using LabSolutions version 5 software. Measurements were carried out at $40^{\circ} \mathrm{C}$. The mobile phase was water and acetonitrile. The mass spectrometer was interfaced with the liquid chromatograph using an electrospray ion source. The nitrogen nebulizing gas flow was set at $10 \mathrm{~L} \mathrm{~min}^{-1}$ and the drying gas flow at $15 \mathrm{~mL} \mathrm{~min}^{-1} .4500 \mathrm{~V}$ were used for the interface voltage. The temperature of the block heater was maintained at $400{ }^{\circ} \mathrm{C}$ and the one of the desolvation line at $250{ }^{\circ} \mathrm{C}$. The MRM transitions and collision energy were as follows: $544.2 \rightarrow 361.2(-25 \mathrm{eV}) / 321.0$ (-25 eV) for Dox, $876.3 \rightarrow 531.3(-30 \mathrm{eV}) / 307.9(-30 \mathrm{eV})$ for PTX, 746.4 $\rightarrow 714.3(-35 \mathrm{eV}) / 534.1(-35 \mathrm{eV}) / 471.3(-35 \mathrm{eV})$ for MMAF-OMe, $567.1 \rightarrow 263.1(-35 \mathrm{eV}) / 231.3(-35 \mathrm{eV})$ for Mytoxin A. The collision gas used was argon at $230 \mathrm{kPa}$. The dwell time was set to $100 \mathrm{msec}$ and the pause time to $3 \mathrm{msec}$. 


\section{Supplementary figures}

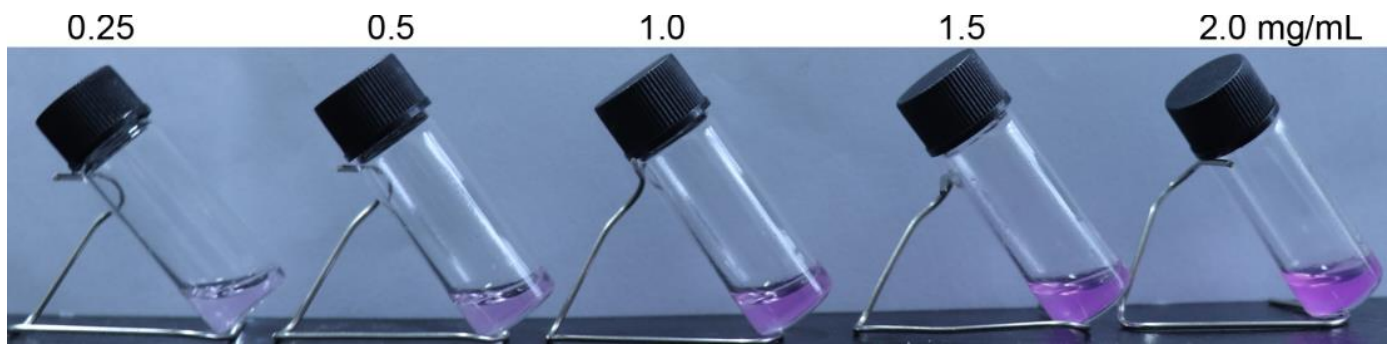

Figure S1. Optical images of NapFFYpK-Tz treated with alkaline phosphatase. The critical hydrogelation concentration is $0.5 \mathrm{mg} / \mathrm{mL}$. $10 \mathrm{mg} / \mathrm{mL}$ stock solution of NapFFYpK-Tz was prepared by dissolving compound NapFFYpK-Tz in PBS and adjusting the solution $\mathrm{pH}$ to 7.4 using $1 \mathrm{~mol} / \mathrm{L} \mathrm{NaOH}$. Then, the stock solution was diluted to $0.25-2.0 \mathrm{mg} / \mathrm{mL}$. To $0.5 \mathrm{~mL}$ of solution at each concentration, 10 $\mathrm{U} / \mathrm{mL}$ of alkaline phosphatase was added. After $24 \mathrm{~h}$, the hydrogels formed at $0.5-2.0 \mathrm{mg} / \mathrm{mL}$.

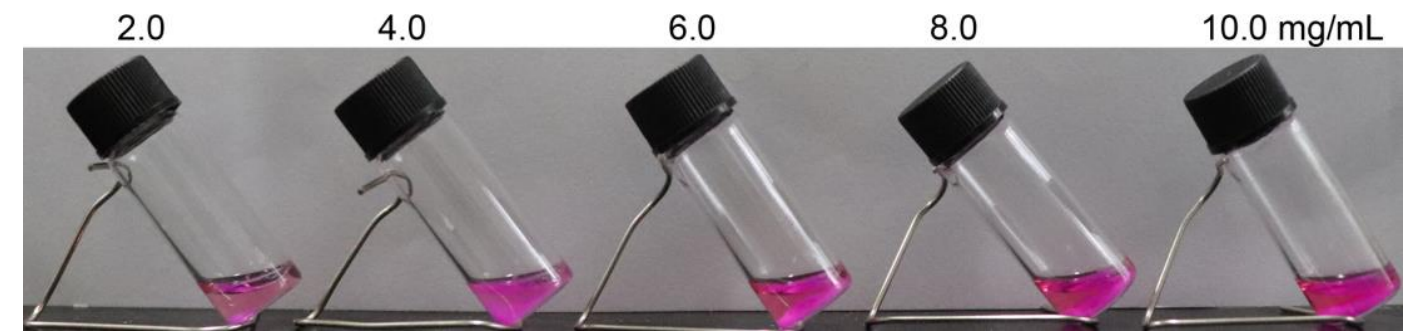

Figure S2. Optical images of NapYpK-Tz treated with alkaline phosphatase. Precipitates were observed and there is no hydrogel formed at the concentration of $2.0-10.0 \mathrm{mg} / \mathrm{mL}$ NapYpK-Tz. $20 \mathrm{mg} / \mathrm{mL}$ stock solution of NapYpK-Tz was prepared by dissolving compound NapYpK-Tz in PBS and adjusting the solution $\mathrm{pH}$ to 7.4 using $1 \mathrm{~mol} / \mathrm{L} \mathrm{NaOH}$. Then, the stock solution was diluted to $2.0-10.0 \mathrm{mg} / \mathrm{mL}$. To $0.5 \mathrm{~mL}$ solution at each concentration, $10 \mathrm{U} / \mathrm{mL}$ of alkaline phosphatase was added. After $24 \mathrm{~h}$, the precipitates formed at $2.0-10.0 \mathrm{mg} / \mathrm{mL}$.

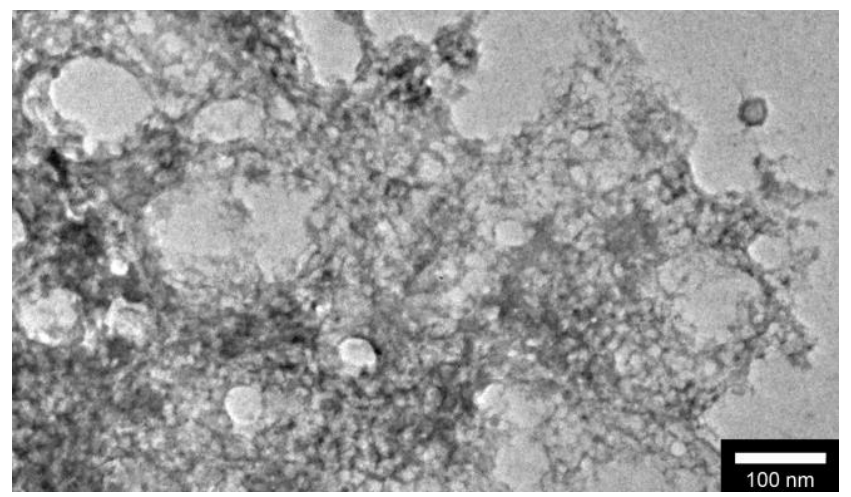

Figure S3. TEM image of the precipitate of NapYpK-Tz treated with alkaline phosphatase. The precipitate was prepared from the solution of $2.0 \mathrm{mg} / \mathrm{mL}$ of NapYpK-Tz in PBS at pH 6.5 treated with 10 $\mathrm{U} / \mathrm{mL}$ of $\mathrm{ALP}$. 


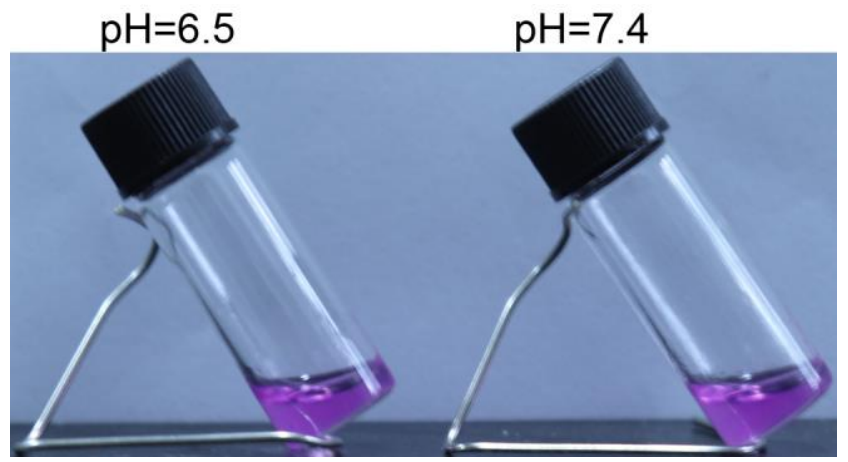

Figure S4. Optical images of hydrogel of NapFFYK-Tz. $2 \mathrm{mg} / \mathrm{mL}$ solution of NapFFYK-Tz was prepared by dissolving compound NapFFYK-Tz in PBS and adjusting the solution pH to 6.5 and 7.4 using $1 \mathrm{~mol} / \mathrm{L} \mathrm{NaOH}$. After $24 \mathrm{~h}$, a soft hydrogel formed at $\mathrm{pH} 6.5$.

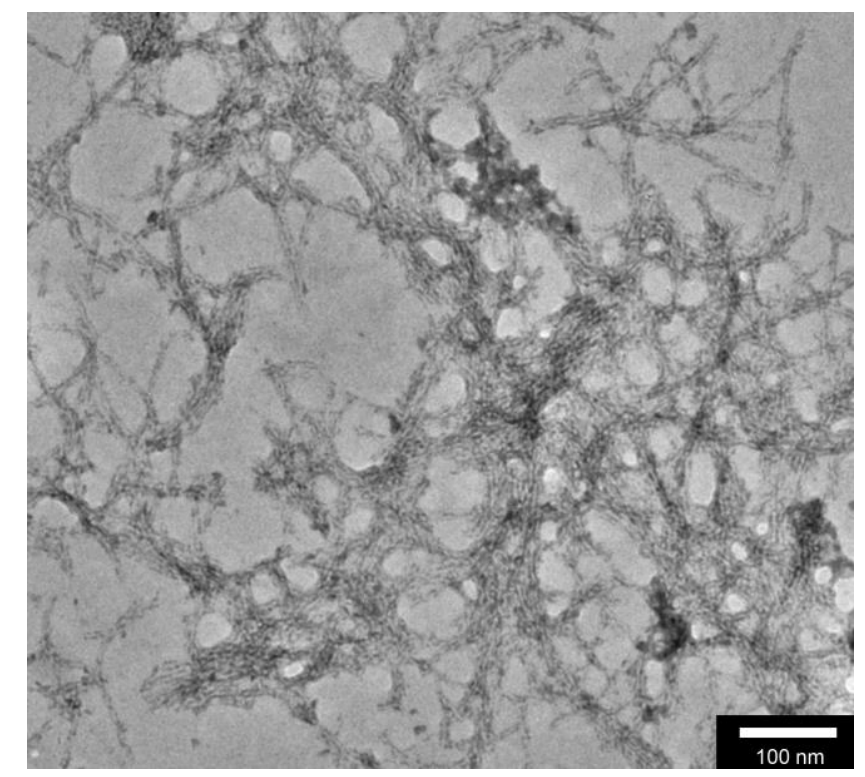

Figure S5. TEM image of nanofibers in hydrogel of NapFFYK-Tz. TEM image shows there is a network of uniform nanofibers with a diameter of $5.9 \pm 0.5 \mathrm{~nm}$ in the hydrogel of NapFFYK-Tz prepared from $2.0 \mathrm{mg} / \mathrm{mL}$ NapFFYK-Tz solution at $\mathrm{pH} 6.5$. 


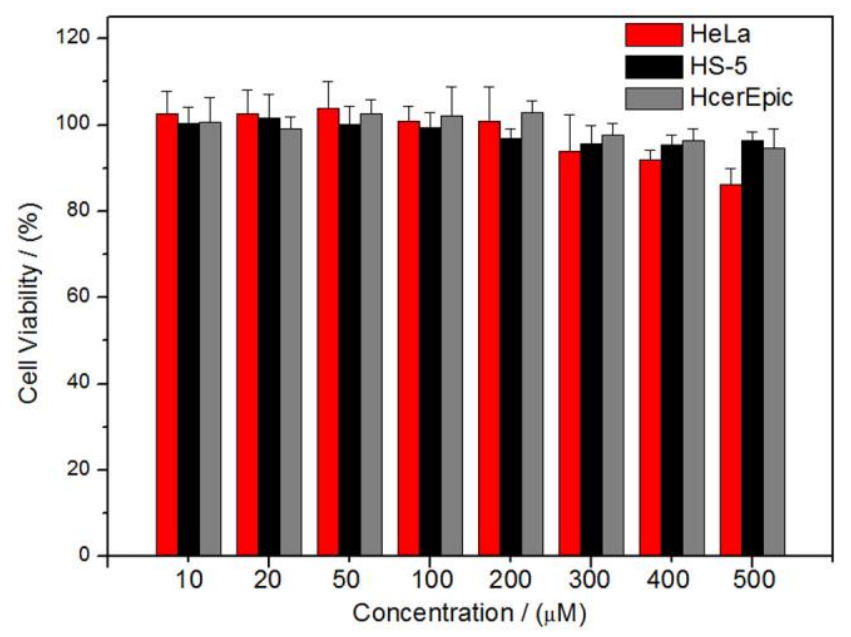

Figure S6. The $72 \mathrm{~h}$ cytotoxicity of NapFFYpK-Tz against HeLa cells, HS- 5 cells and HcerEpic cells. Cells at a density of $5 \times 10^{3}$ cells per well were incubated with $100 \mu \mathrm{L}$ of pre-warmed medium containing 10-500 $\mu \mathrm{M}$ NapFFYpK-Tz for $72 \mathrm{~h}$. Cell proliferation was then assessed by MTT assay $(n=6)$.

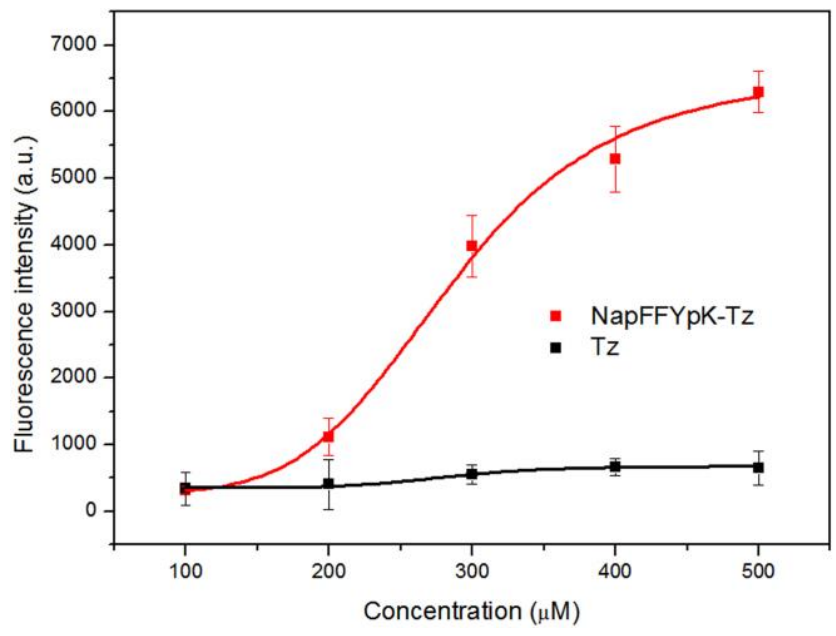

Figure S7. Accumulation of Tz bearing self-assembly precursors in live A2780T cells. Cells were pre-incubated with $100 \mu \mathrm{L}$ of 100-500 $\mu \mathrm{M}$ self-assembly precursors NapFFYpK-Tz or tetrazine (Tz) for $6 \mathrm{~h}$, rinsed with PBS and incubated with $100 \mu \mathrm{L}$ of $50 \mu \mathrm{M}$ TCO-CMR for $24 \mathrm{~h}(\mathrm{n}=6)$. 


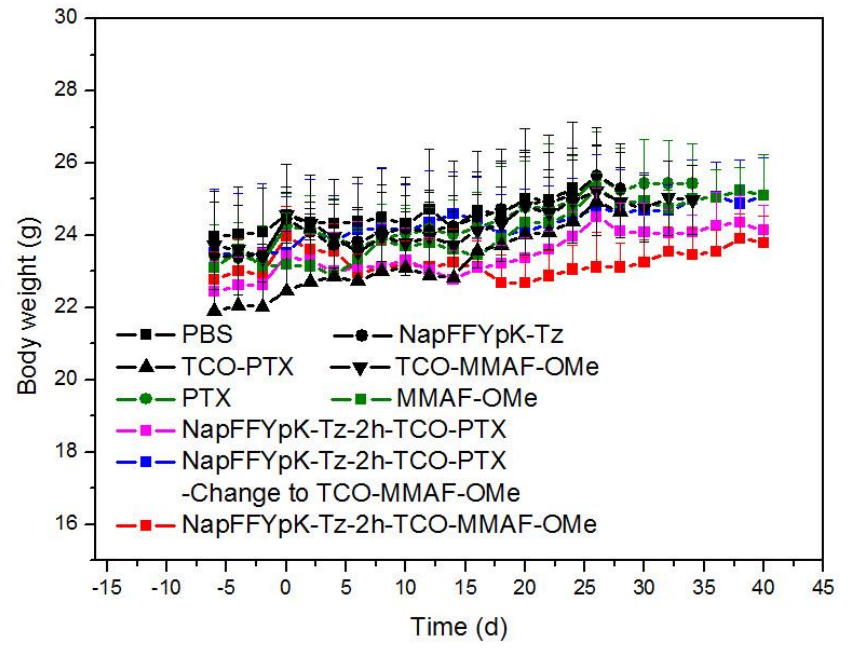

Figure S8. Body weight change of mice in each group. (Sacrificed mice in the MMAF-OMe group were excluded for analysis of body weight.) 


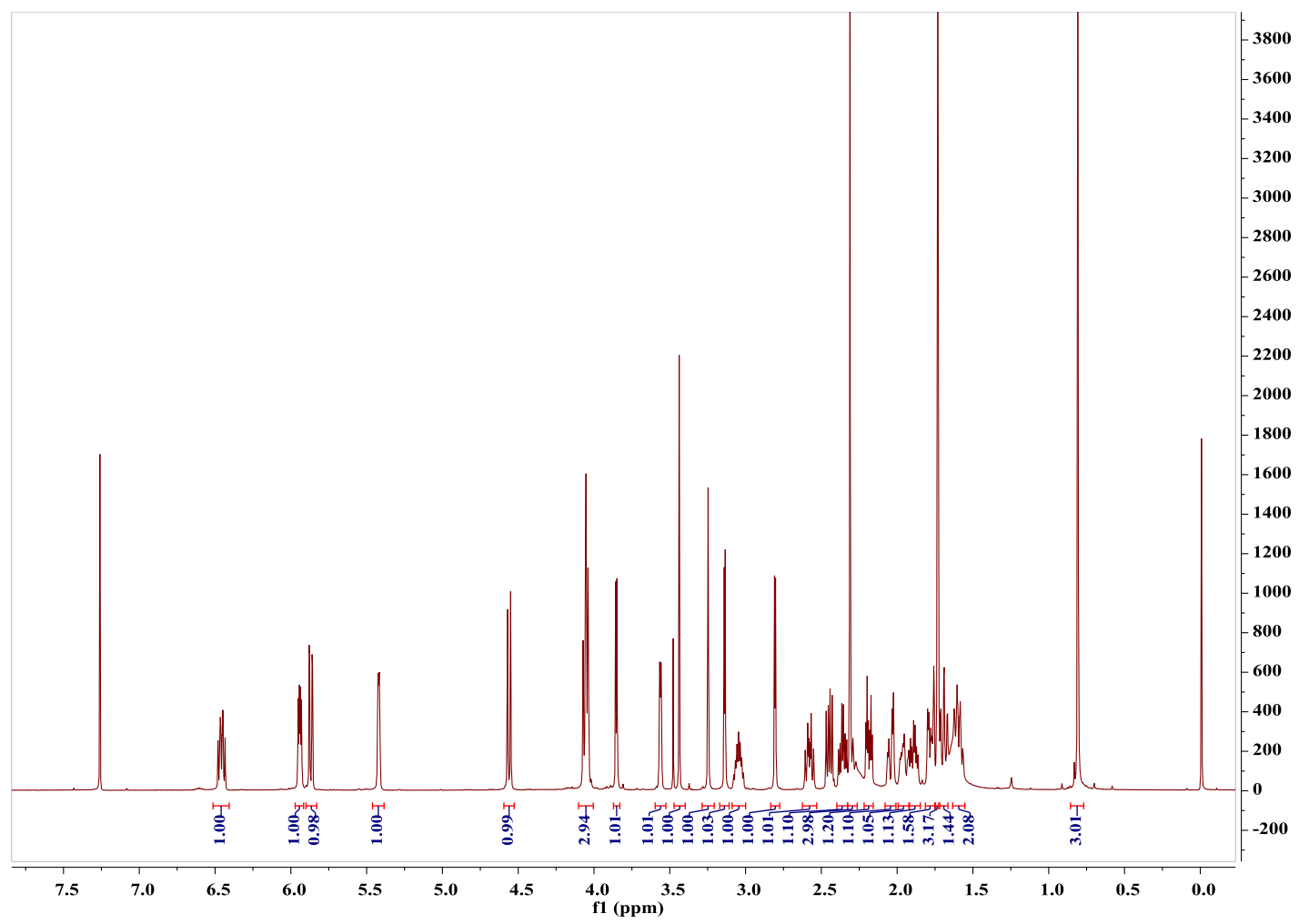

Figure S9. ${ }^{1} \mathrm{H}$ NMR spectrum $\left(\mathrm{CDCl}_{3}\right)$ of Mytoxin A.

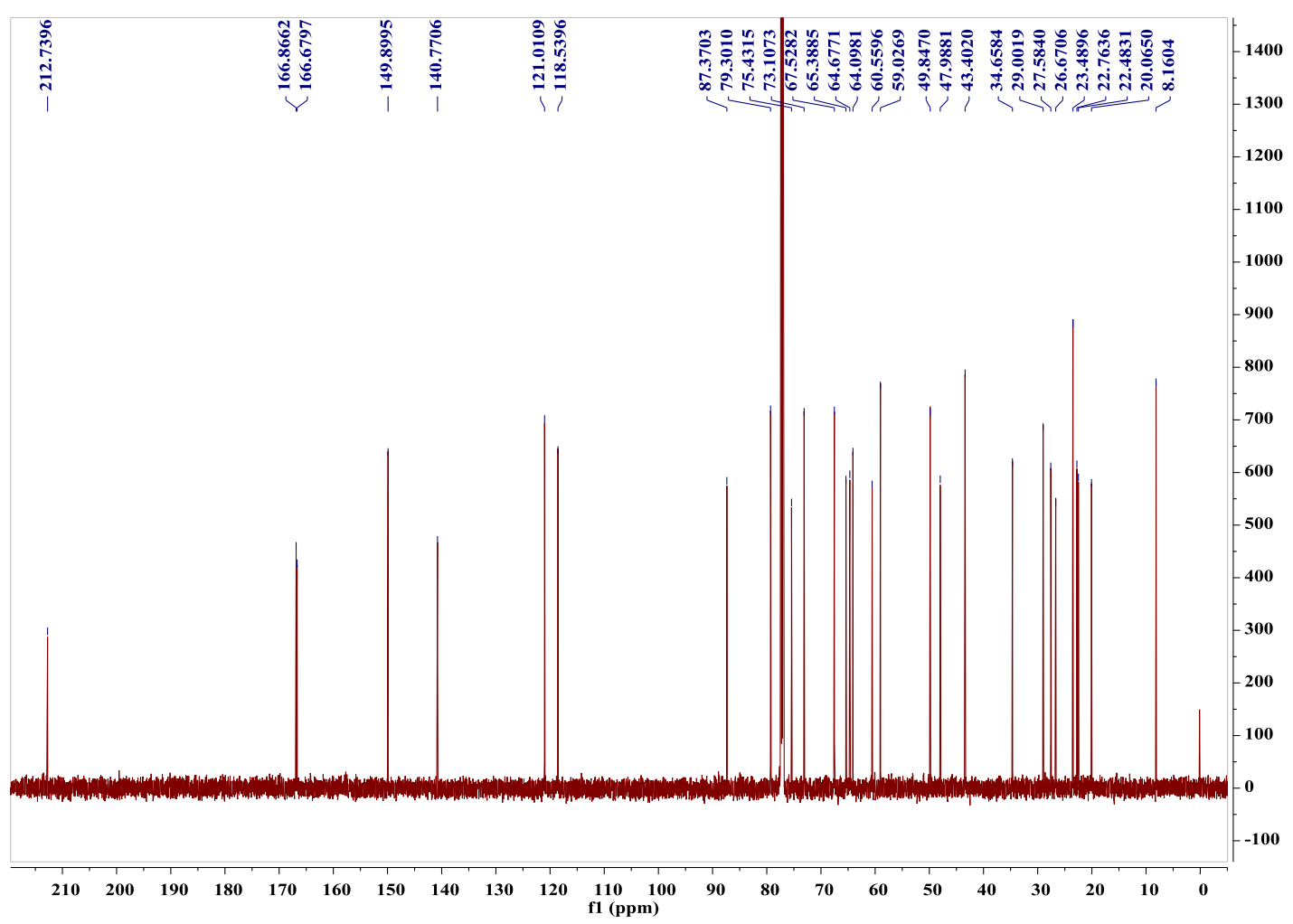

Figure S10. ${ }^{13} \mathrm{C}$ NMR spectrum $\left(\mathrm{CDCl}_{3}\right)$ of Mytoxin A. 


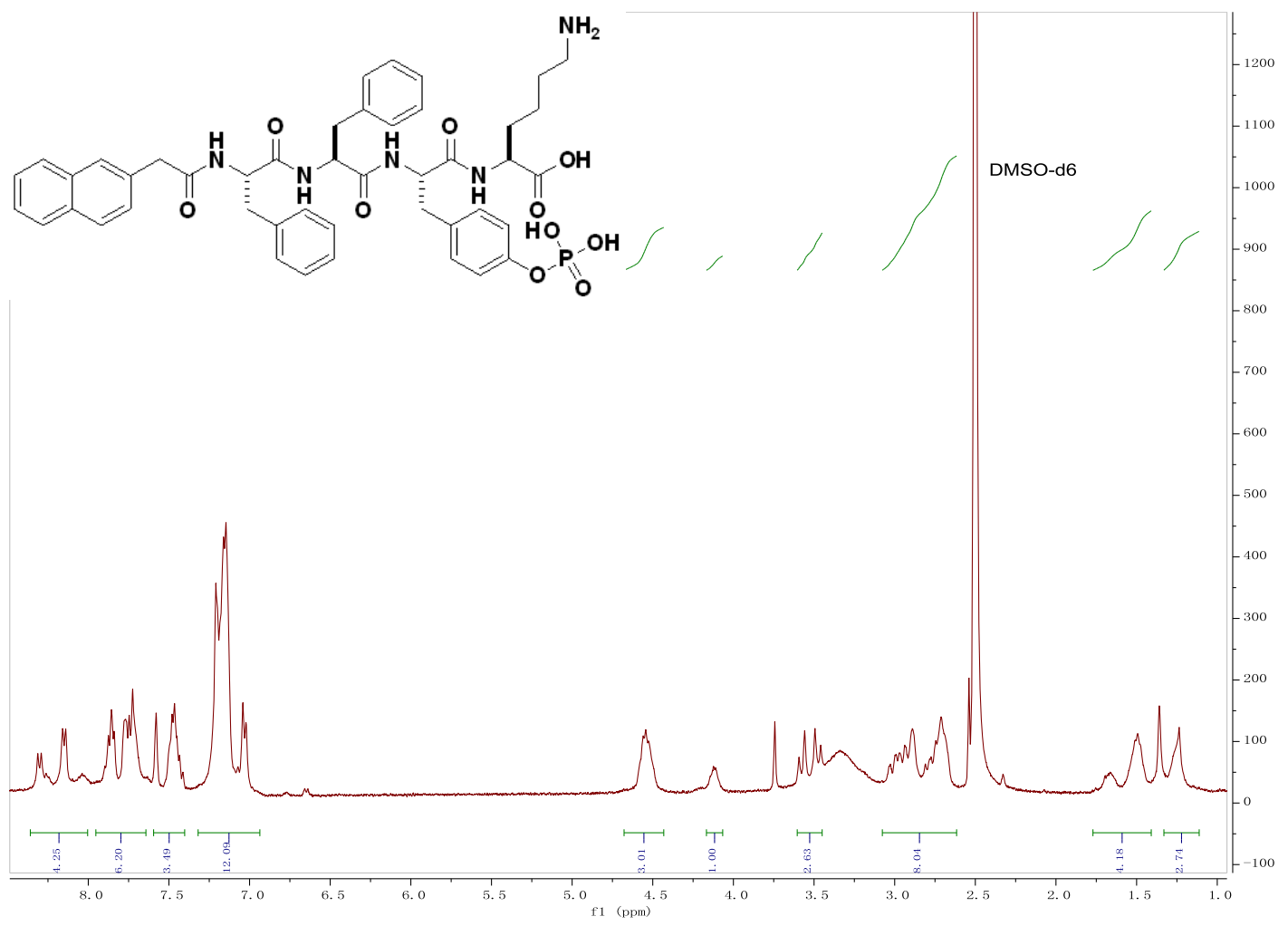

Figure S11. ${ }^{1} \mathrm{H}$ NMR spectrum (DMSO-d6) of NapFFYpK.

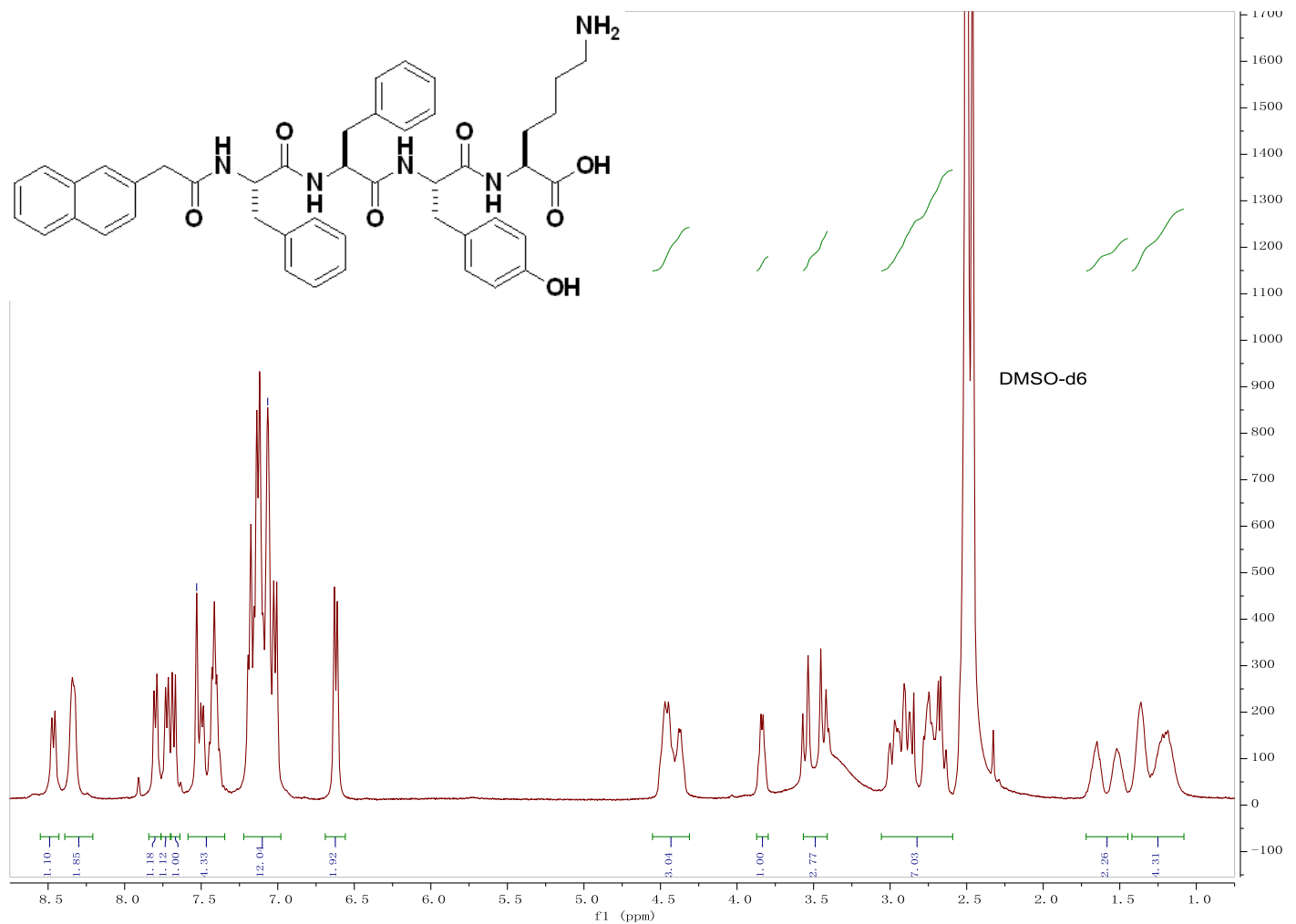

Figure S12. ${ }^{1} \mathrm{H}$ NMR spectrum (DMSO-d6) of NapFFYK. 


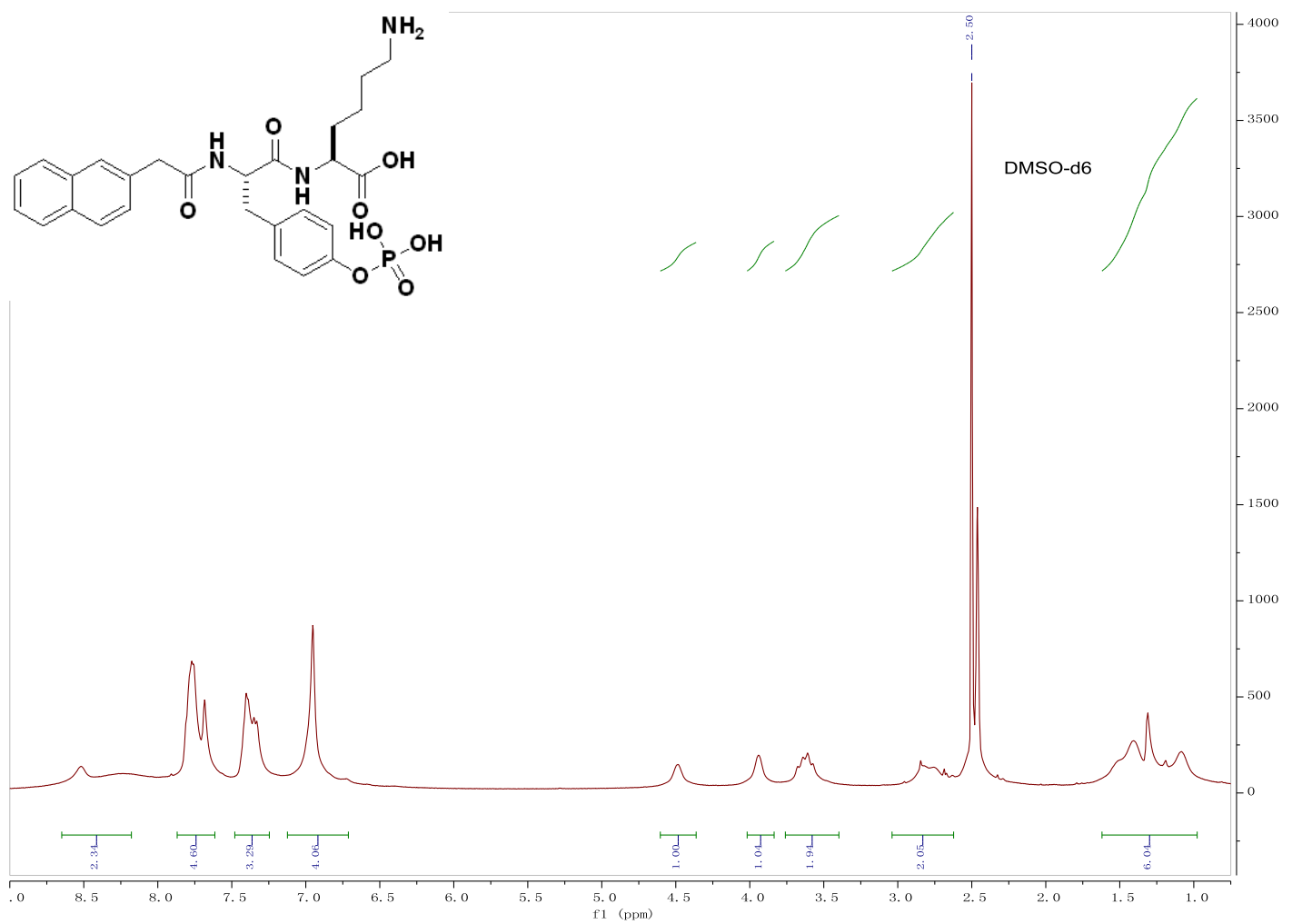

Figure S13. ${ }^{1} \mathrm{H}$ NMR spectrum (DMSO-d6) of NapYpK.

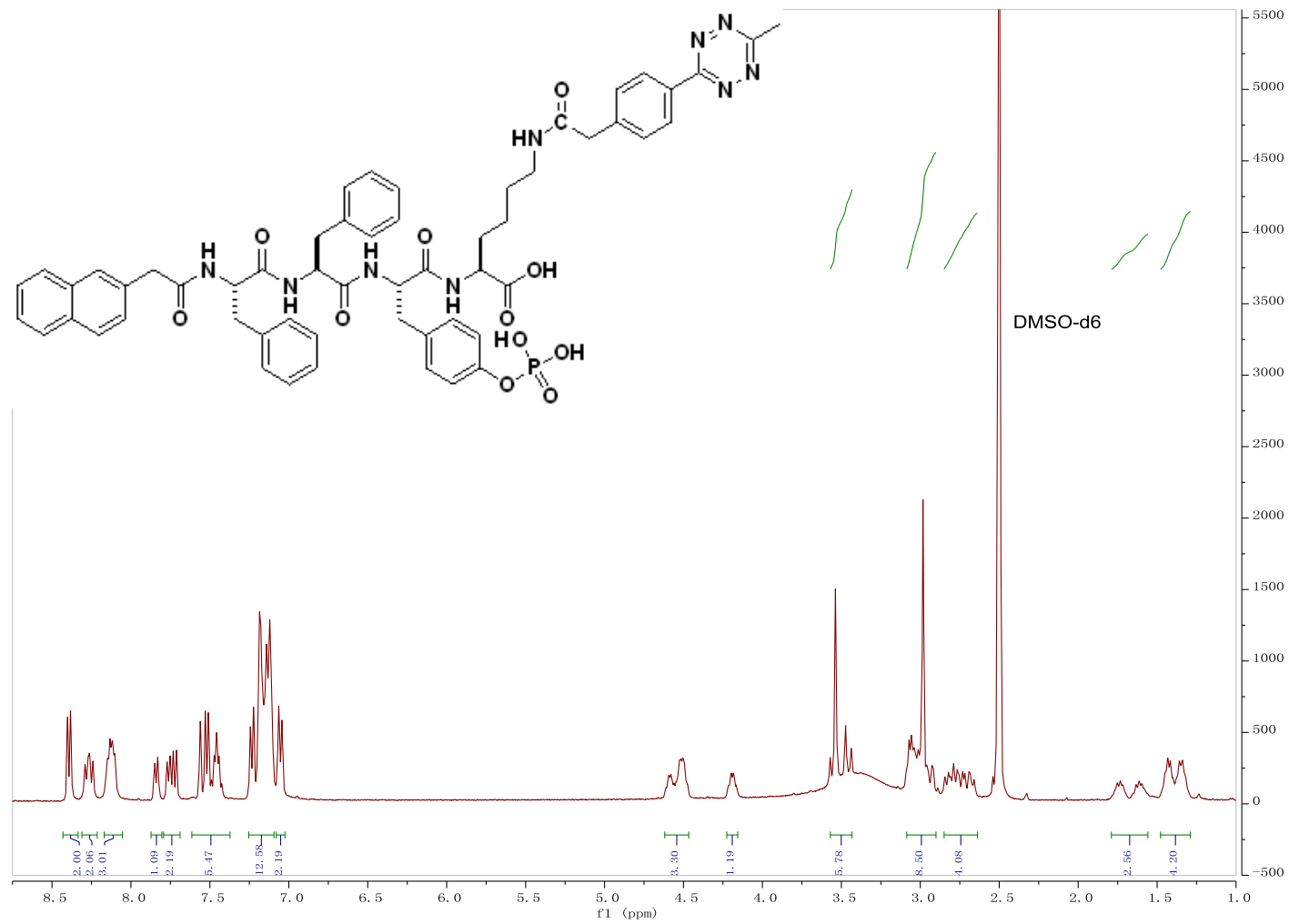

Figure S14. ${ }^{1} \mathrm{H}$ NMR spectrum (DMSO-d6) of NapFFYpK-Tz. 


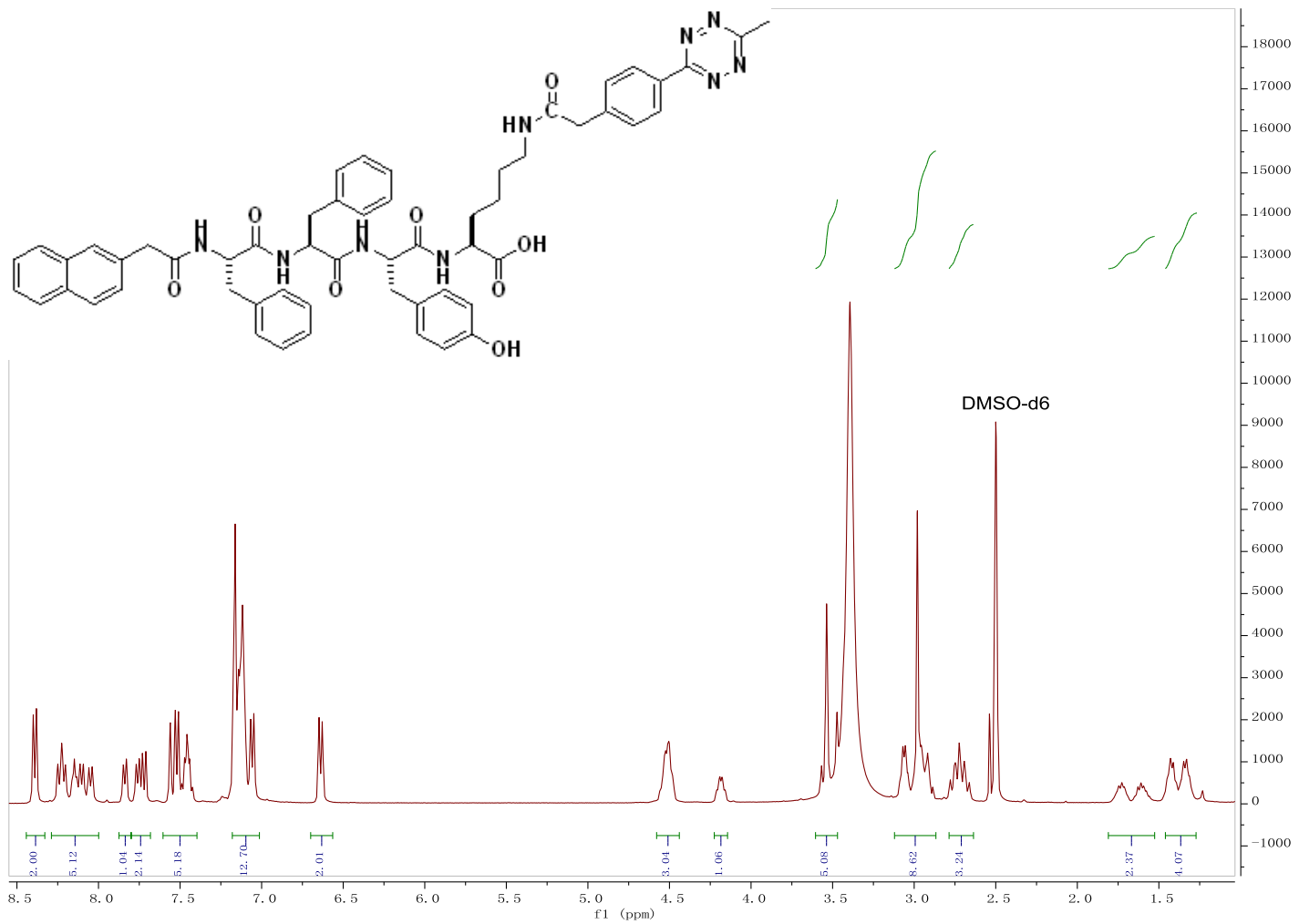

Figure S15. ${ }^{1} \mathrm{H}$ NMR spectrum (DMSO-d6) of NapFFYK-Tz.

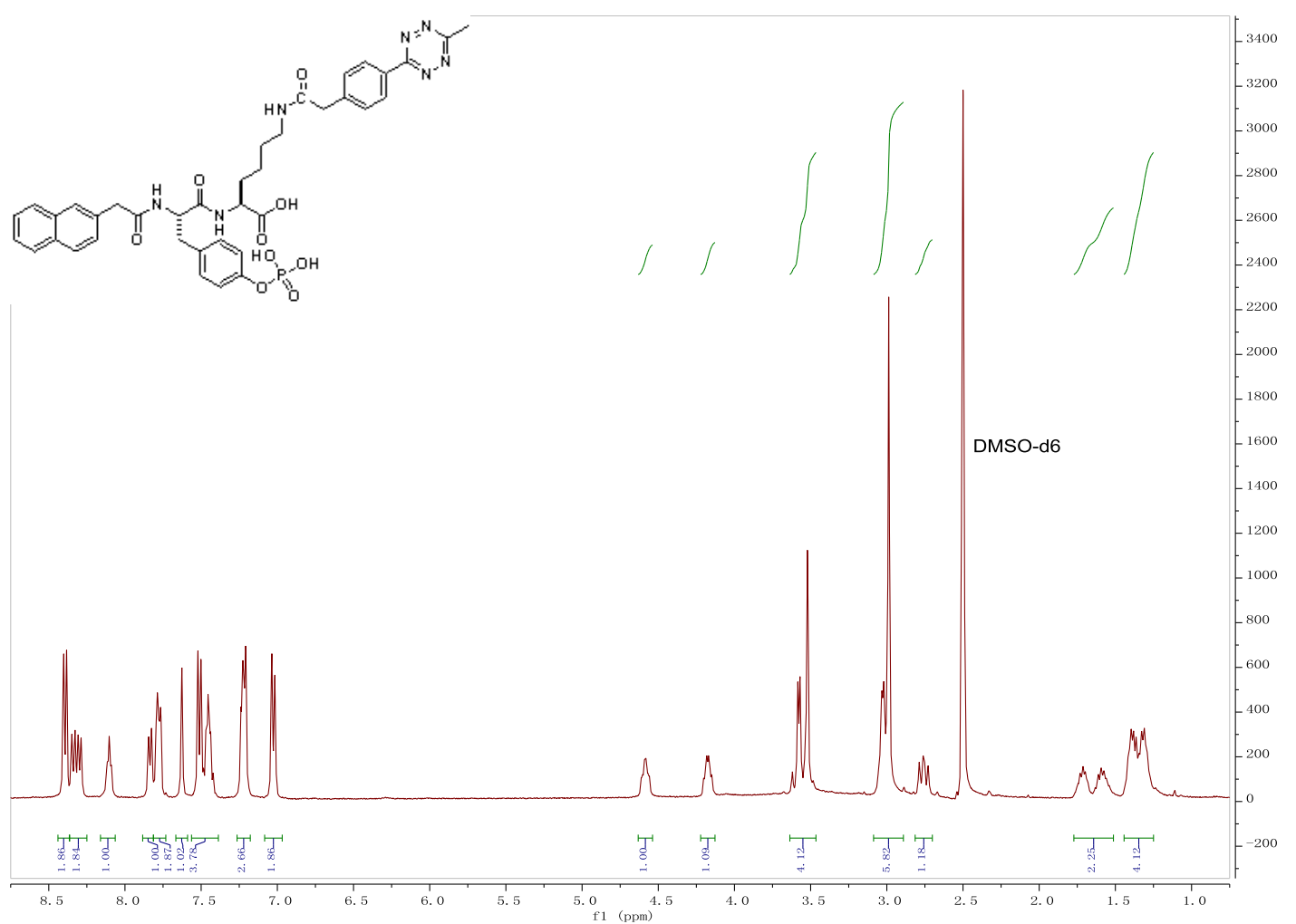

Figure S16. ${ }^{1} \mathrm{H}$ NMR spectrum (DMSO-d6) of NapYpK-Tz. 


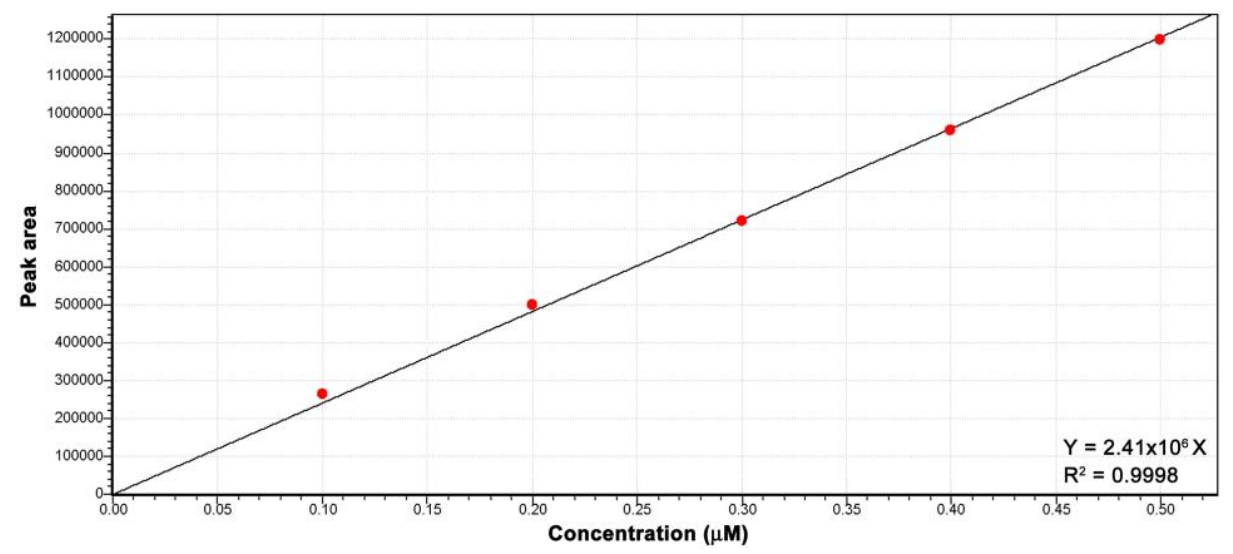

Figure S17. Calibration curve of Dox. 


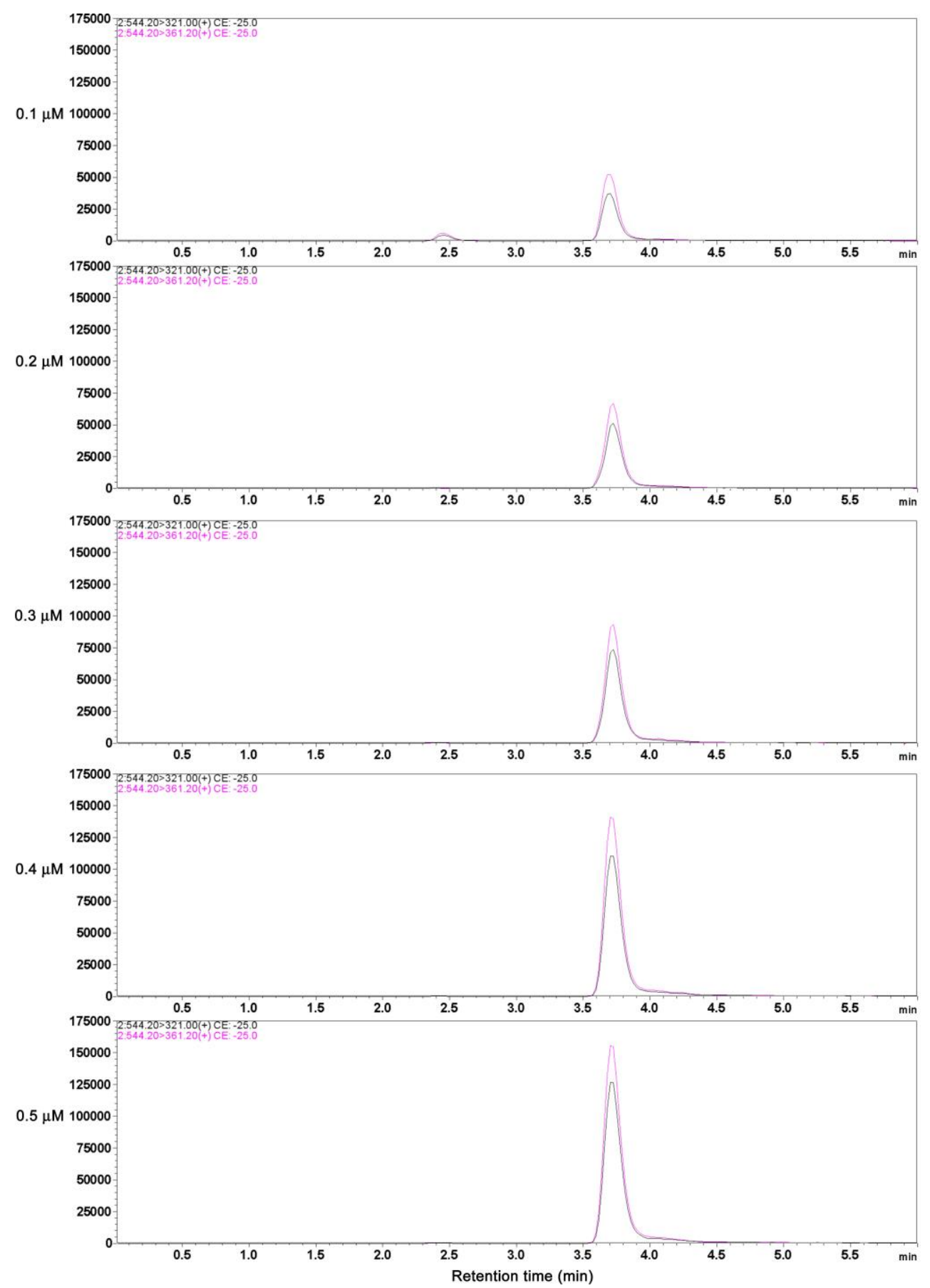

Figure S18. HPLC chromatograms of Dox. 


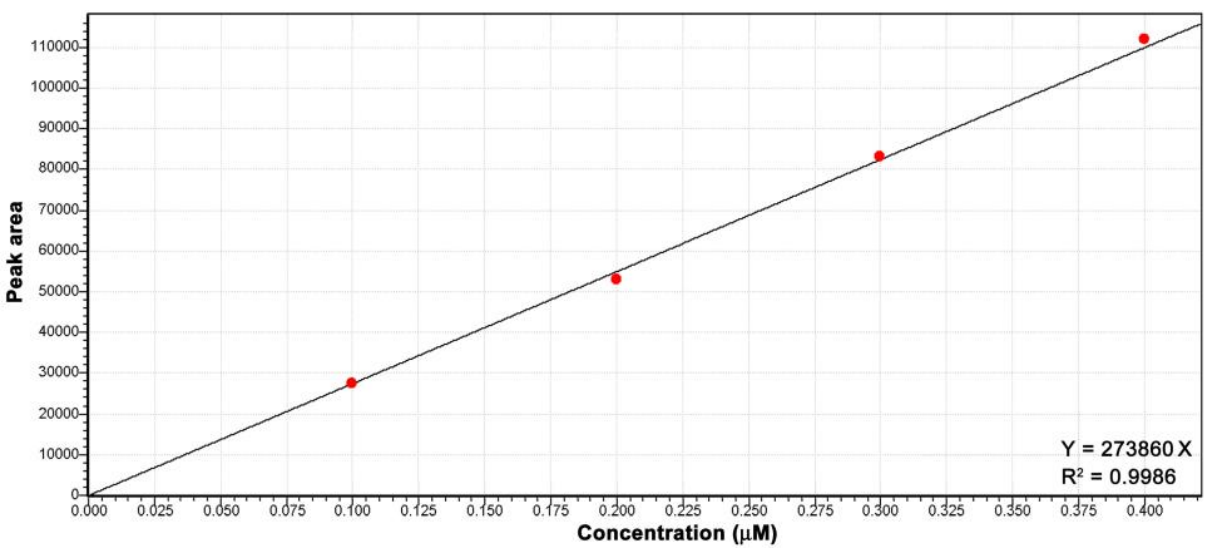

Figure S19. Calibration curve of PTX.
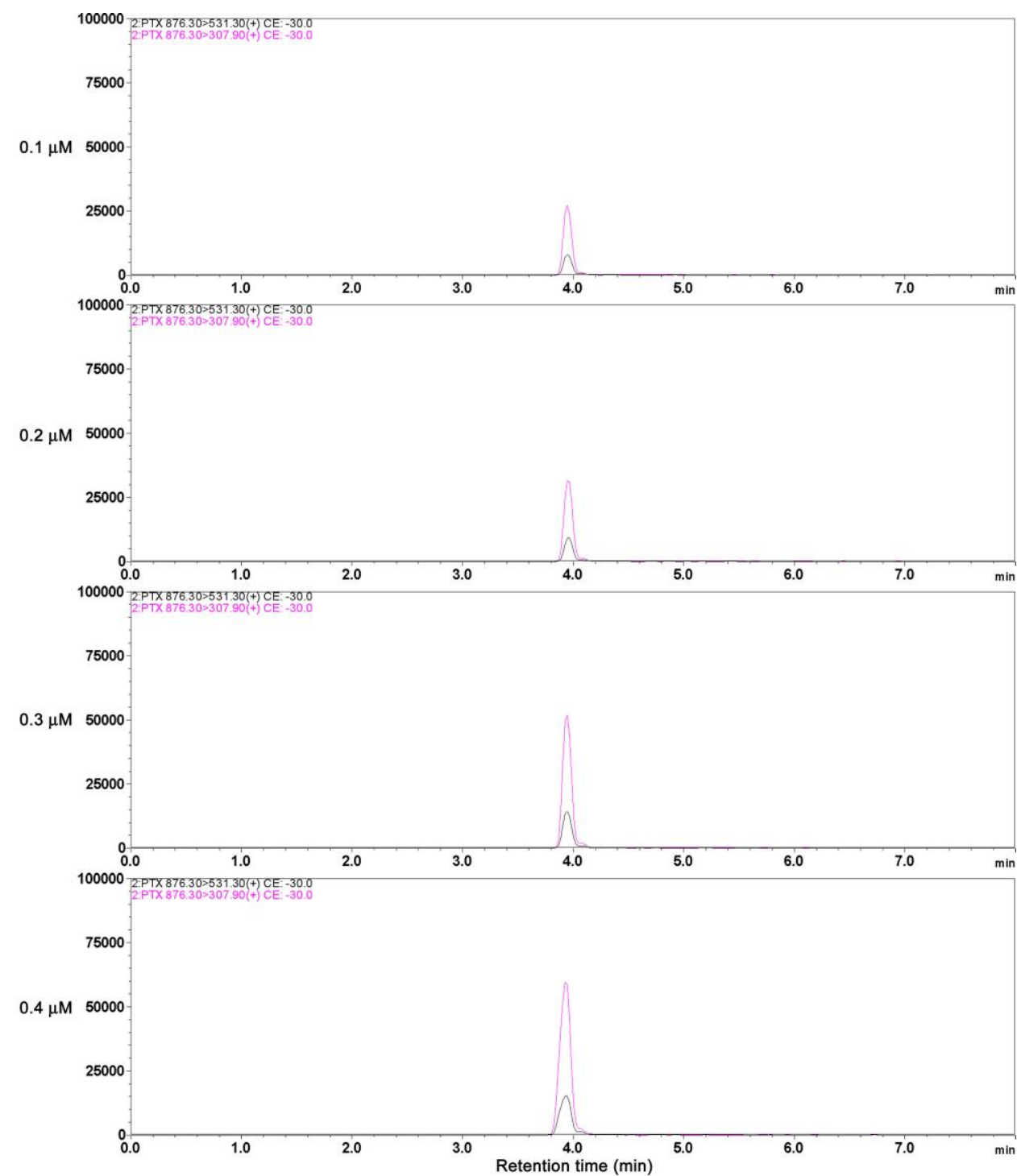

Figure S20. HPLC chromatograms of PTX. 


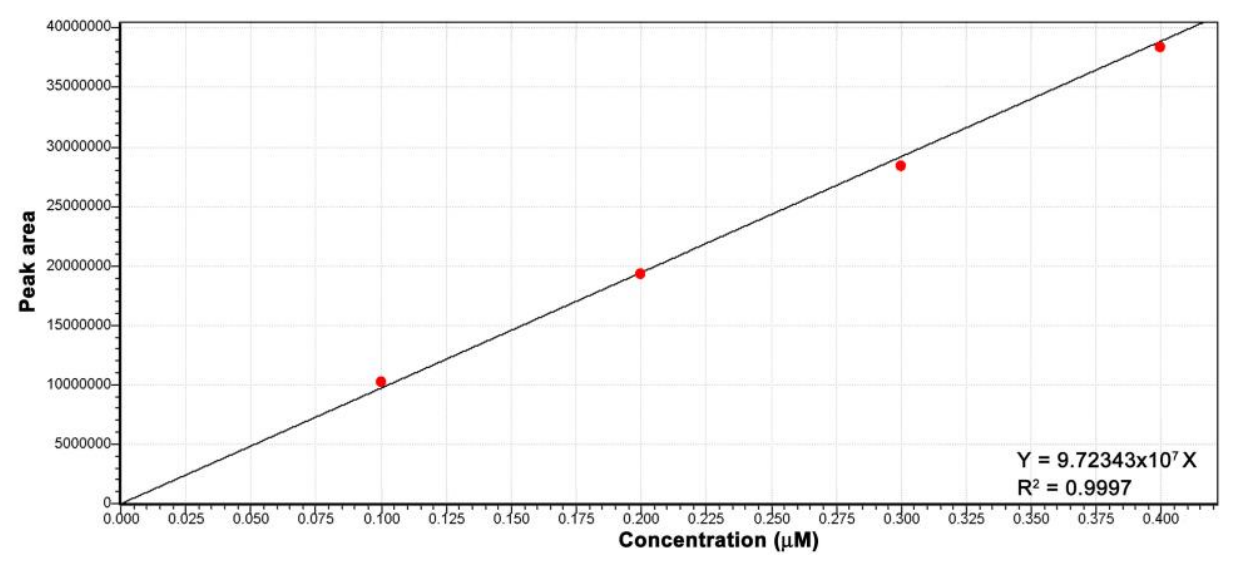

Figure S21. Calibration curve of MMAF-OMe.

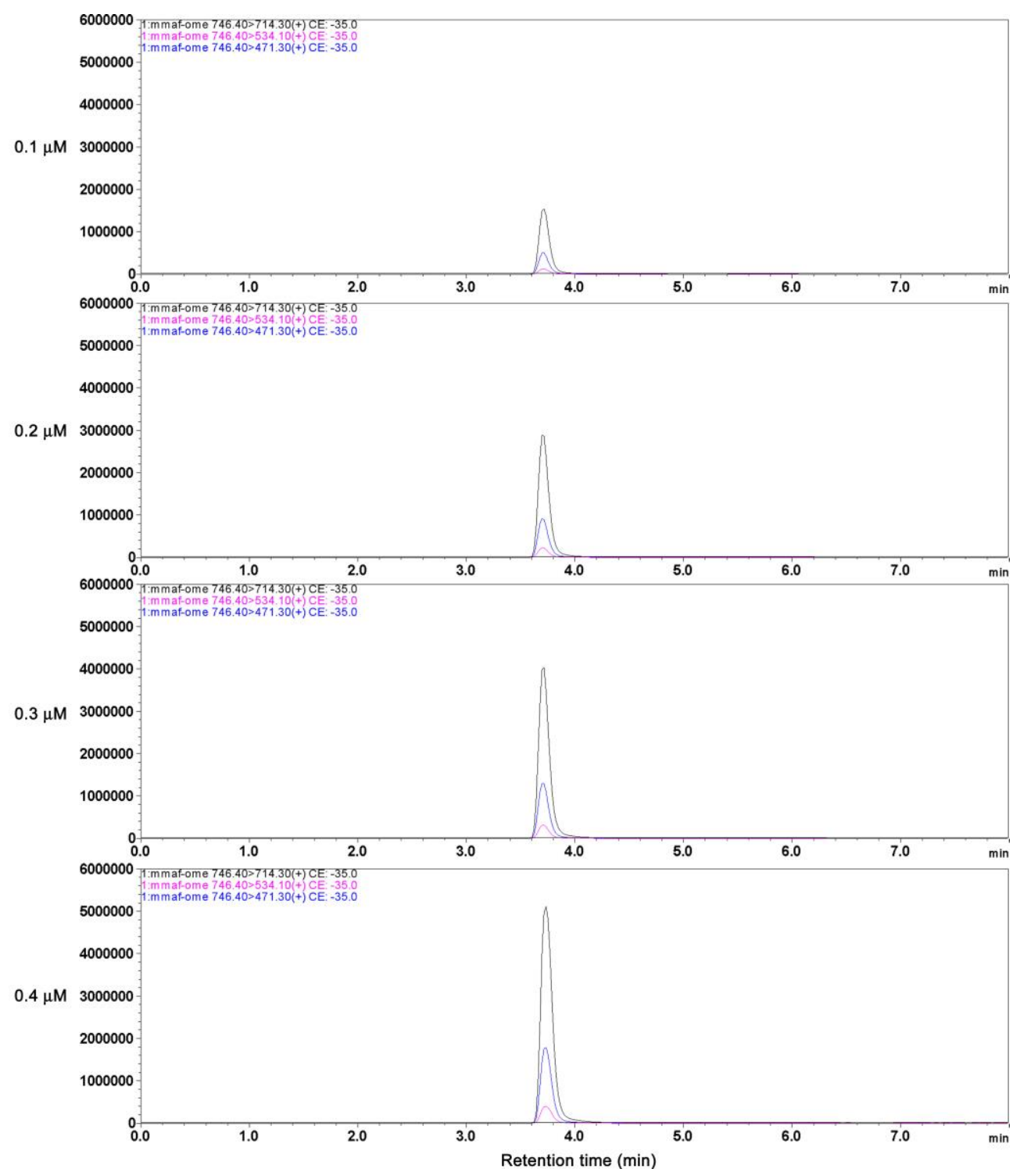

Figure S22. HPLC chromatograms of MMAF-OMe. 


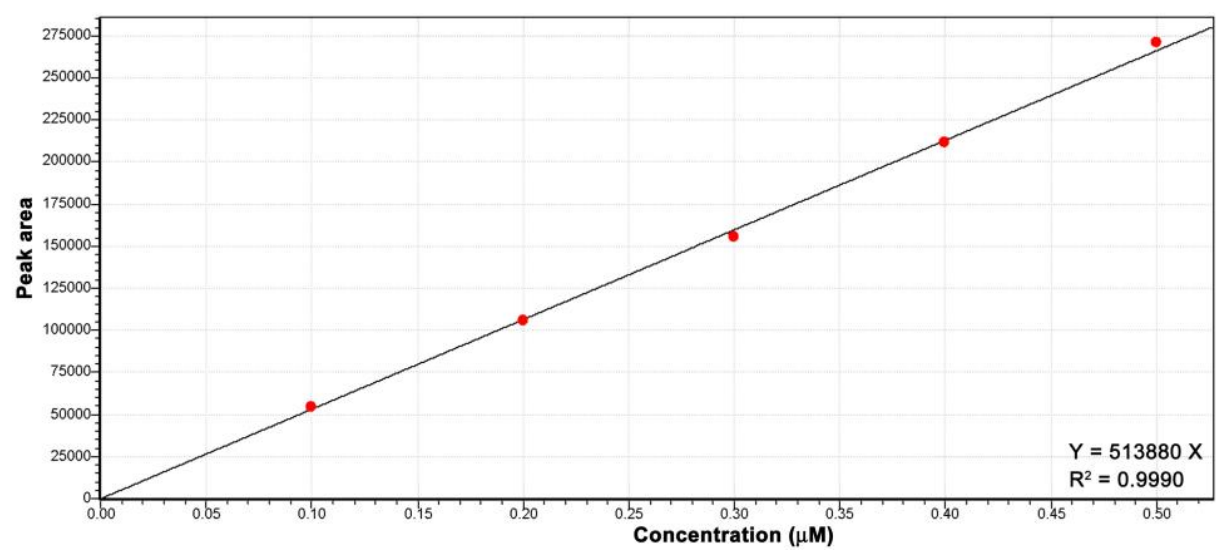

Figure S23. Calibration curve of Mytoxin A.
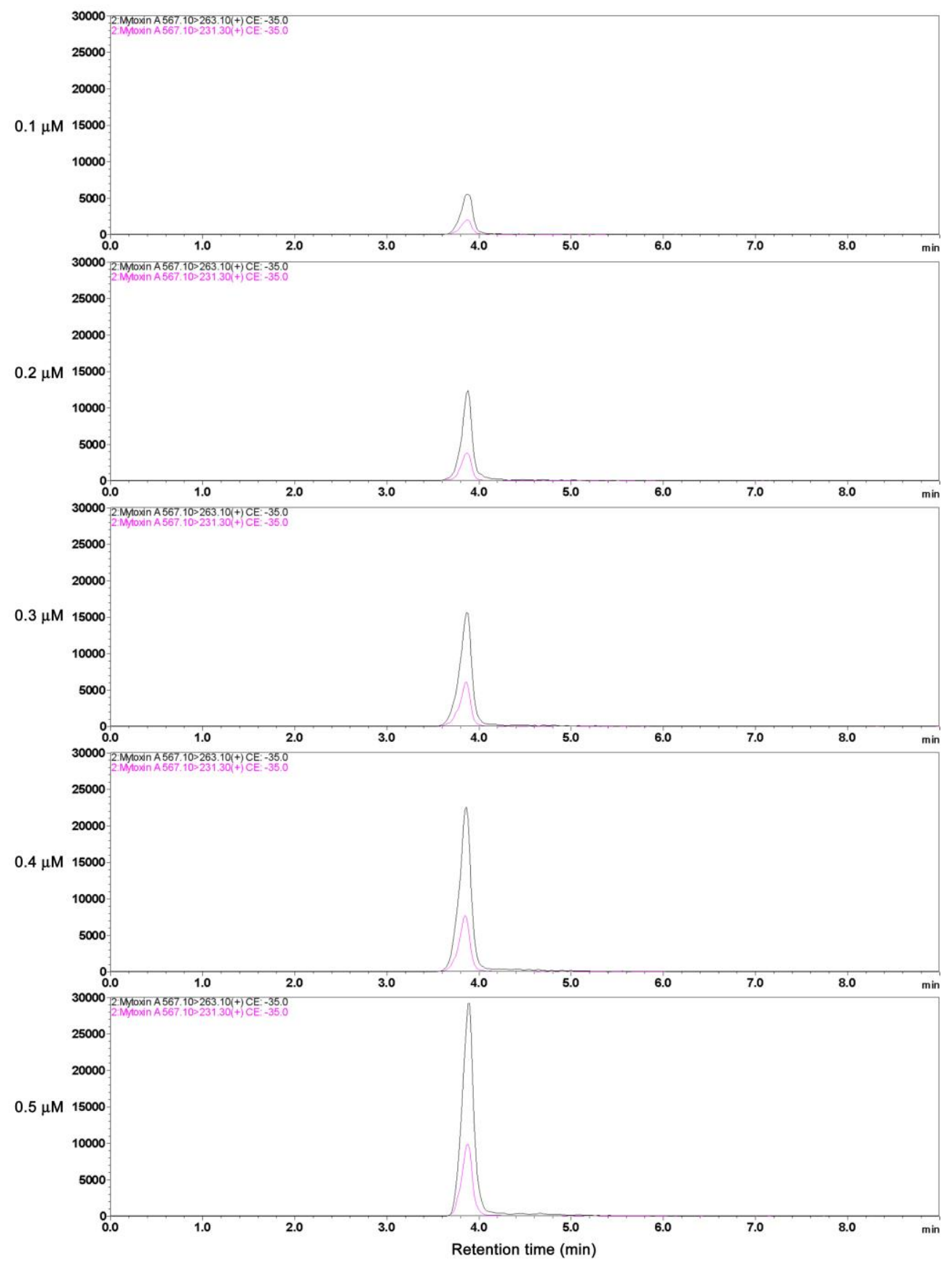

Figure S24. HPLC chromatograms of Mytoxin A. 


\section{References}

1. Yao Q. X., et al. Synergistic enzymatic and bioorthogonal reactions for selective prodrug activation in living systems. Nat. Commun. 9, 5032 (2018).

2. Fan X. Y., et al. Optimized tetrazine derivatives for rapid bioorthogonal decaging in living cells. Angew. Chem. Int. Ed. 55, 14046-14050 (2016). 